\title{
Three years of greenhouse gas column-averaged dry air mole fractions retrieved from satellite - Part 2: Methane
}

\author{
O. Schneising ${ }^{1}$, M. Buchwitz ${ }^{1}$, J. P. Burrows ${ }^{1}$, H. Bovensmann ${ }^{1}$, P. Bergamaschi ${ }^{2}$, and W. Peters ${ }^{3}$ \\ ${ }^{1}$ Institute of Environmental Physics (IUP), University of Bremen FB1, Bremen, Germany \\ ${ }^{2}$ Institute for Environment and Sustainability (IES), European Commission Joint Research Centre (EC-JRC), Ispra, Italy \\ ${ }^{3}$ Dept. of Meteorology and Air Quality, Wageningen Univ. and Research Centre (WUR), Wageningen, The Netherlands
}

Received: 27 February 2008 - Published in Atmos. Chem. Phys. Discuss.: 5 May 2008

Revised: 10 December 2008 - Accepted: 10 December 2008 - Published: 19 January 2009

\begin{abstract}
Carbon dioxide $\left(\mathrm{CO}_{2}\right)$ and methane $\left(\mathrm{CH}_{4}\right)$ are the two most important anthropogenic greenhouse gases. SCIAMACHY on ENVISAT is the first satellite instrument whose measurements are sensitive to concentration changes of the two gases at all altitude levels down to the Earth's surface where the source/sink signals are largest. We have processed three years (2003-2005) of SCIAMACHY nearinfrared nadir measurements to simultaneously retrieve vertical columns of $\mathrm{CO}_{2}$ (from the $1.58 \mu \mathrm{m}$ absorption band), $\mathrm{CH}_{4}(1.66 \mu \mathrm{m})$ and oxygen $\left(\mathrm{O}_{2}\right.$ A-band at $\left.0.76 \mu \mathrm{m}\right)$ using the scientific retrieval algorithm WFM-DOAS. We show that the latest version of WFM-DOAS, version 1.0, which is used for this study, has been significantly improved with respect to its accuracy compared to the previous versions while essentially maintaining its high processing speed $(\sim 1$ min per orbit, corresponding to $\sim 6000$ single measurements, and per gas on a standard PC). The greenhouse gas columns are converted to dry air column-averaged mole fractions, denoted $\mathrm{XCO}_{2}$ (in ppm) and $\mathrm{XCH}_{4}$ (in ppb), by dividing the greenhouse gas columns by simultaneously retrieved dry air columns. For $\mathrm{XCO}_{2}$ dry air columns are obtained from the retrieved $\mathrm{O}_{2}$ columns. For $\mathrm{XCH}_{4}$ dry air columns are obtained from the retrieved $\mathrm{CO}_{2}$ columns because of better cancellation of light path related errors compared to using $\mathrm{O}_{2}$ columns retrieved from the spectrally distant $\mathrm{O}_{2}$ Aband. Here we focus on a discussion of the $\mathrm{XCH}_{4}$ data set. The $\mathrm{XCO}_{2}$ data set is discussed in a separate paper (Part 1). For 2003 we present detailed comparisons with the TM5 model which has been optimally matched to highly accurate but sparse methane surface observations. After accounting for a systematic low bias of $\sim 2 \%$ agreement with TM5 is typically within $1-2 \%$. We investigated to what extent the SCIAMACHY $\mathrm{XCH}_{4}$ is influenced by the variability
\end{abstract}

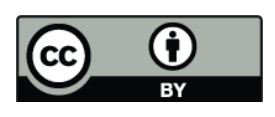

Correspondence to: $\mathrm{M}$. Buchwitz (michael.buchwitz@iup.physik.unibremen.de) of atmospheric $\mathrm{CO}_{2}$ using global $\mathrm{CO}_{2}$ fields from NOAA's $\mathrm{CO}_{2}$ assimilation system CarbonTracker. We show that the $\mathrm{CO}_{2}$ corrected and uncorrected $\mathrm{XCH}_{4}$ spatio-temporal pattern are very similar but that agreement with TM5 is better for the CarbonTracker $\mathrm{CO}_{2}$ corrected $\mathrm{XCH}_{4}$. In line with previous studies (e.g., Frankenberg et al., 2005b) we find higher methane over the tropics compared to the model. We show that tropical methane is also higher when normalizing the $\mathrm{CH}_{4}$ columns with retrieved $\mathrm{O}_{2}$ columns instead of $\mathrm{CO}_{2}$. In consistency with recent results of Frankenberg et al. (2008b) it is shown that the magnitude of the retrieved tropical methane is sensitive to the choice of the spectroscopic line parameters of water vapour. Concerning inter-annual variability we find similar methane spatio-temporal pattern for 2003 and 2004. For 2005 the retrieved methane shows significantly higher variability compared to the two previous years, most likely due to somewhat larger noise of the spectral measurements.

\section{Introduction}

Methane $\left(\mathrm{CH}_{4}\right)$ is a potent greenhouse gas and plays important roles in atmospheric chemistry. Considering a time horizon of 100 years, one kilogram of methane emitted into the atmosphere warms our atmosphere about 25 times more than a kilogram of carbon dioxide does (IPCC, 2007). Increasing $\mathrm{CH}_{4}$ concentrations lead to increasing concentrations of the pollutant ozone in the troposphere (Dentener et al., 2005). Furthermore, $\mathrm{CH}_{4}$ consumes the hydroxyl radical $(\mathrm{OH})$, the most important cleansing agent of our atmosphere (see, e.g., Lelieveld (2006), and references given therein). Atmospheric methane has more than doubled since pre-industrial times, mainly as a result of rice cultivation, animal farming, and waste handling, contributing as much as $20 \%$ to the anthropogenic greenhouse effect (IPCC, 2001, 2007). Fortunately, methane levels were rather stable from

Published by Copernicus Publications on behalf of the European Geosciences Union. 
1999 to 2006 but the reason for this is not well understood. Bousquet et al. (2006) suggested that this stabilization may be due to a downward trend of anthropogenic emissions between the late 1980s and the late 1990s.

They further conclude that year-to-year variability is dominated by wetland emissions and that atmospheric methane concentrations may rise again in the near future if wetland emissions return to their mean 1990s levels. Actually, recent measurements by global monitoring networks show a renewed methane growth starting near the beginning of 2007 (Rigby et al., 2008). Important issues in this context are climate feedbacks caused by methane release from melting permafrost regions as this amplifies warming trends. Therefore, monitoring of the atmospheric methane is required, and, in order to reliably predict future concentrations, an adequate understanding of its variable sources and sinks. Information on methane sources and sinks can be obtained via inverse modeling from measured atmospheric methane concentrations (see, e.g., Bergamaschi et al., 2005, 2007; Mikaloff Fletcher et al., 2004a,b; Houweling et al., 1999; Hein et al., 1997).

The spectral near-infrared nadir measurements of the SCIAMACHY instrument on board the European environmental satellite ENVISAT are sensitive to concentration changes of the two most important greenhouse gases carbon dioxide $\left(\mathrm{CO}_{2}\right)$ and methane at all atmospheric altitude levels, including the boundary layer, where the surface source signal is largest. Using the latest version of the scientific Weighting Function Modified DOAS retrieval algorithm (WFM-DOAS version 1.0), which is described in this manuscript, we have processed three years (2003-2005) of global SCIAMACHY data to simultaneously retrieve vertical columns of $\mathrm{CO}_{2}, \mathrm{CH}_{4}$ and oxygen $\left(\mathrm{O}_{2}\right)$. Whereas the $\mathrm{CO}_{2}$ data set is discussed in Schneising et al. (2008a) (Part 1), the methane data set is presented in this manuscript (Part 2).

Inverse modeling of the methane sources and sinks on the global scale using highly precise and accurate surface measurements mostly based on weekly flask sampling has been studied by, for example, Hein et al. (1997), Houweling et al. (1999), and Bousquet et al. (2006). These studies revealed that methane surface flux uncertainty reduction strongly depends on the spatial scale with typically significant reduction on the continental scale but only marginal reduction at regional scales due to the sparseness of the ground-based network. Recently Bergamaschi et al. (2005) presented a detailed discussion of the inverse modeling of methane for individual countries by using also continuous surface measurements focusing on Europe.

Detailed regional information on the global scale can be obtained from satellite measurements of the methane vertical column or its column-averaged mixing ratio, provided the satellite data are precise $(\sim 1-2 \%)$ and systematic biases, especially regionally dependent biases, can be avoided or are well characterized (Meirink et al., 2006). Recently, Bergamaschi et al. (2007) reported about the first inverse modeling attempt using satellite data. The methane data set used by Bergamaschi et al. (2007) has been retrieved from the SCIAMACHY instrument using the Iterative Maximum A Posteriori-DOAS (IMAP-DOAS) retrieval algorithm (Frankenberg et al., 2006). Very encouraging results have been obtained but also some problems had been identified, for example, an apparent time dependent latitudinal bias which was attributed recently to a certain extent to potential inaccuracies in the spectroscopic parameters of methane (Frankenberg et al., 2008a).

Both approaches, IMAP-DOAS and WFM-DOAS, are independently developed scientific retrieval algorithms which differ in several aspects including the underlying radiative transfer model, the handling of albedo variations, its atmospheric input parameters, and the definition of the state vector (or fit parameters), but also have several aspects in common. Most importantly, both approaches use data from the same instrument and similar spectral regions to retrieve methane columns. In addition, the main data product of the two algorithms is the column-averaged dry air mole fraction of methane, $\mathrm{XCH}_{4}$, which is defined as the absolute column of methane (in number of molecules per surface area) divided by the dry air column. The $\mathrm{XCH}_{4}$ is the preferred quantity for inverse modeling compared to the total column amount as the spatial pattern of the total column is dominated by topographic features and surface pressure changes (as methane is relatively well mixed) whereas methane variations due to sources and sinks are typically much smaller (about $3 \%$ at maximum). The dry air column can be obtained by the simultaneous measurement of a well mixed gas with well known mole fraction, exhibiting less variability than methane, such as oxygen $\left(\mathrm{O}_{2}\right)$. Although we discuss some results obtained by normalizing methane by oxygen, our main $\mathrm{XCH}_{4}$ data product (and also the data product discussed in Frankenberg et al., 2006) is obtained by using simultaneously measured $\mathrm{CO}_{2}$ columns, retrieved from a spectral window located close to the spectral window from which the methane columns are retrieved. This approach typically results in higher accuracy and precision due to better cancellation of (light path related) errors when the $\mathrm{CH}_{4}$ to $\mathrm{CO}_{2}$ column ratio is computed, compared to normalizing with $\mathrm{O}_{2}$ columns obtained from the spectrally distant $\mathrm{O}_{2}$ A-band.

In order to assess the quality of the methane data set, comparisons have been made with independent methane column measurements. Dils et al. (2006b) have performed a comparison for the years 2003 and 2004 using seven European ground-based Fourier Transform Spectroscopy (FTS) stations and found reasonable to good agreement. As the comparison with the FTS is limited to a few stations we have performed a detailed comparison of the global data set using inverse $\mathrm{CH}_{4}$ model simulations, based on the TM5 model (Krol et al., 2005) which has been optimized versus highly accurate methane measurements at the Earth's surface from the NOAA/ESRL network (Bergamaschi et al., 2007). The results are presented in Sect. 5. As our methane data 
product is influenced by the variability of atmospheric $\mathrm{CO}_{2}$ we investigated to what extent the agreement with TM5 depends on applying a correction using $\mathrm{CO}_{2}$ from a state of the art global $\mathrm{CO}_{2}$ model. For this purpose we used NOAA's global $\mathrm{CO}_{2}$ assimilation system CarbonTracker (Peters et al., 2007), which is also based on the TM5 transport model. Our methane measurements confirm the findings of Frankenberg et al. (2005b) of higher tropical methane compared to current models even though the magnitude of the retrieved enhancement is sensitive to the choice of spectroscopy. In order to demonstrate that the high tropical methane is not an artifact of lower than assumed $\mathrm{CO}_{2}$, we compared our $\mathrm{XCH}_{4}$ data product with a second one obtained by normalizing with simultaneously measured oxygen $\left(\mathrm{O}_{2}\right)$ instead of $\mathrm{CO}_{2}$.

This manuscript is organized as follows: In Sect. 2 the SCIAMACHY instrument and its measurement principle are shortly introduced and explained. This is followed by a description of the WFM-DOAS retrieval algorithm in Sect. 3 and an error analysis in Sect. 4. The new SCIAMACHY multi-year methane data set is discussed in Sect. 5 followed by a discussion of the impact of updated spectroscopy on the WFM-DOAS retrievals in Sect. 6. Conclusions are given in Sect. 7.

\section{The SCIAMACHY instrument}

SCIAMACHY (Burrows et al., 1990; Burrows and Chance, 1991; Burrows et al., 1995; Bovensmann et al., 1999) is a grating spectrometer, which is a multi-national (Germany, The Netherlands, Belgium) contribution to the European environmental satellite ENVISAT measuring reflected, backscattered and transmitted solar radiation in the spectral region $214-2380 \mathrm{~nm}$ at moderate spectral resolution $(0.2-$ $1.4 \mathrm{~nm}$ ). Each of the eight spectral channels comprises a grating and a 1024 element monolithic diode array.

ENVISAT was launched into a sun synchronous orbit in descending node having an Equator crossing time of 10:00 a.m. and is mainly performing a sequence of alternating nadir and limb observations on the Earth's day side. These measurements can be inverted to obtain a large number of atmospheric data products (Bovensmann et al., 1999) including the column amounts of $\mathrm{CH}_{4}, \mathrm{CO}_{2}$ and $\mathrm{O}_{2}$ which are relevant for this study. The horizontal resolution of the nadir measurements depends on orbital position and spectral interval, but is typically $60 \mathrm{~km}$ across track times $30 \mathrm{~km}$ along track for the absorption features in the fitting windows used in this study.

Overall, the in-flight optical performance of SCIAMACHY is very similar to that predicted from the pre-flight on ground characterization and calibration activities. An exception is a time dependent optical throughput variation in the SCIAMACHY near-infrared (NIR) channel 7 and channel 8 (which was designated to be the main $\mathrm{CH}_{4}$ channel) due to in-flight deposition of ice on the detectors. This ad- versely affects the trace gas retrieval by reducing the signal to noise and changing the instrument function (Gloudemans et al., 2005; Buchwitz et al., 2005b). The WFM-DOAS version 1.0 results presented in this manuscript have been derived using $\mathrm{CH}_{4}$ and $\mathrm{CO}_{2}$ absorption features in channel 6 $(1000-1750 \mathrm{~nm})$, which are not affected by an ice-layer, as their detectors operate at higher temperatures.

\section{WFM-DOAS retrieval algorithm}

The retrieval of a long-lived and therefore relatively wellmixed gas such as methane is challenging as only the small variations on top of a large background yield information on its surface sources and sinks. The retrieval algorithm therefore has to meet the conflicting requirements of accuracy and speed in order to process the large amounts of data produced by SCIAMACHY. This is achieved by the Weighting Function Modified Differential Optical Absorption Spectroscopy (WFM-DOAS) retrieval technique (Buchwitz et al., 2000b; Buchwitz and Burrows, 2004; Buchwitz et al., 2005a,b) developed at the University of Bremen for the retrieval of trace gases and optimized for $\mathrm{CO}_{2}, \mathrm{CH}_{4}$ and $\mathrm{O}_{2}$ retrievals using a fast look-up table (LUT) scheme to avoid computationally expensive online radiative transfer calculations. The algorithm has been described in detail elsewhere (Buchwitz et al., 2000b; Buchwitz and Burrows, 2004; Buchwitz et al., $2005 a, b)$. We therefore focus on a discussion of the main differences between the current version 1.0, which has been used to generate the data set discussed in this manuscript, and the previous version 0.5 (Buchwitz et al., 2006a; Dils et al., 2006a). These differences are the same as for $\mathrm{CO}_{2}$ (Schneising et al., 2008a) and are shortly summarized in the following subsection.

\subsection{Retrieval of vertical columns}

WFM-DOAS is a least-squares method based on scaling (or shifting) pre-selected atmospheric vertical profiles. The fit parameters for the trace gases yield directly the desired vertical columns. The logarithm of a linearized radiative transfer model plus a low-order polynomial $P_{i}(\hat{\boldsymbol{a}})$ is fitted to the logarithm of the ratio of the measured nadir radiance and solar irradiance spectrum, i.e., the observed sun-normalized radiance $I^{\text {obs }}$. The least-squares WFM-DOAS equation can be written as follows (the fit parameter vectors or vector components are indicated by a hat):

$$
\sum_{i=1}^{m}\left(\ln I_{i}^{\text {obs }}-\ln I_{i}^{\bmod }(\hat{\boldsymbol{V}}, \hat{\boldsymbol{a}})\right)^{2} \equiv\|\boldsymbol{R} \boldsymbol{E} \boldsymbol{S}\|^{2} \rightarrow \min .
$$

where the linearized radiative transfer model is given by 


$$
\begin{aligned}
\ln I_{i}^{\bmod }(\hat{\boldsymbol{V}}, \hat{\boldsymbol{a}}) & =\ln I_{i}^{\bmod }(\overline{\boldsymbol{V}}) \\
& +\left.\sum_{j=1}^{J} \frac{\partial \ln I_{i}^{\bmod }}{\partial V_{j}}\right|_{\bar{V}_{j}} \times\left(\hat{V}_{j}-\bar{V}_{j}\right)+P_{i}(\hat{\boldsymbol{a}})
\end{aligned}
$$

Index $i$ refers to the center wavelength $\lambda_{i}$ of detector pixel number $i$. The components of vector $\boldsymbol{V}$, denoted $V_{j}$, are the vertical columns of all trace gases which have absorption lines in the selected spectral fitting window (interfering gas for the $\mathrm{CO}_{2}$ fit is $\mathrm{H}_{2} \mathrm{O}$; for the $\mathrm{CH}_{4}$ fit interfering gases are $\mathrm{H}_{2} \mathrm{O}$ and $\mathrm{CO}_{2}$ ). The fit parameters are the desired trace gas vertical columns $\hat{V}_{j}$ and the polynomial coefficients which are the components of vector $\hat{\boldsymbol{a}}$. An additional fit parameter also used (but for simplicity omitted in the equations given here) is the shift (in Kelvin) of a pre-selected temperature profile. This fit parameter has been added in order to take the temperature dependence of the trace gas absorption cross-sections into account. The fit parameter values are determined by minimising (in a linear least-squares sense) the difference between observation ( $\ln I_{i}^{\text {obs }}$ ) and WFM-DOAS model (ln $I_{i}^{\text {mod }}$ ), i.e. the "length" of fit residuum vector $\boldsymbol{R} \boldsymbol{E} \boldsymbol{S}$ (with components $\mathrm{RES}_{i}$ ) for all spectral points $\lambda_{i}$ simultaneously. A derivative with respect to a vertical column refers to the change of the top-of-atmosphere radiance caused by a change (here: scaling) of a pre-selected trace gas vertical profile. The WFM-DOAS reference spectra are the logarithm of the sun-normalized radiance and its derivatives. They are computed with a radiative transfer model (Buchwitz et al., 2000a) for assumed (e.g. climatological) "mean" columns $\overline{\boldsymbol{V}}$. Multiple scattering is fully taken into account. The least-squares problem can also be expressed in the following vector/matrix notation: Minimize $\|\mathbf{y}-\mathbf{A} \mathbf{x}\|^{2}$ with respect to $\mathbf{x}$. The solution is $\hat{\mathbf{x}}=\mathbf{C}_{\mathbf{x}} \mathbf{A}^{T} \mathbf{y}$ where $\mathbf{C}_{\mathbf{x}} \equiv\left(\mathbf{A}^{T} \mathbf{A}\right)^{-1}$ is the covariance matrix of solution $\hat{\mathbf{x}}$. The errors of the retrieved columns are estimated as follows (Press et al., 1992): $\sigma_{\hat{V}_{j}}=\sqrt{\left(\mathbf{C}_{\mathbf{x}}\right)_{j j} \times \sum_{i} \operatorname{RES}_{i}^{2} /(m-n)}$, where $\left(\mathbf{C}_{\mathbf{x}}\right)_{j j}$ is the $j$ th diagonal element of the covariance matrix, $m$ is the number of spectral points in the fitting window and $n$ is the number of linear fit parameters.

The $\mathrm{CH}_{4}$ and $\mathrm{CO}_{2}$ columns are retrieved using small spectral fitting windows in the near infrared (1630-1671 nm and 1558-1594 nm, respectively) located in SCIAMACHY channel 6, whereas oxygen, retrieved in order to derive alternative column-averaged dry air mole fractions of $\mathrm{CH}_{4}$ for comparison, is retrieved from a spectrally distant fitting window (755-775 nm, $\mathrm{O}_{2}$ A-band) in SCIAMACHY channel 4. The single (constant) vertical methane profile used to avoid that the measurements are influenced by variations artificially introduced by the retrieval method, along with the vertical column averaging kernels, can be obtained from the WFMDOAS web site (http://www.iup.uni-bremen.de/sciamachy/ NIR_NADIR_WFM_DOAS/index.html).
The main differences between the previous version $\left(\mathrm{XCH}_{4}\right.$ $\mathrm{v} 0.5$ ) and the new version 1.0 are the following (see Schneising et al., 2008a for details):

(i) Better consideration of albedo variability by using albedo retrieval in combination with an extended look-up table and interpolation/extrapolation. The retrieved albedos for the different fitting windows are depicted in Fig. 2 of Schneising et al. (2008a).

(ii) Better consideration of surface elevation changes using an extended look-up table and interpolation/extrapolation instead of the earlier nearest neighbour approach.

(iii) Improved spectroscopy: Using HITRAN 2004 (Rothman et al., 2005) spectroscopic line parameters instead of HITRAN 2000/2001 (Rothman et al., 2003).

(iv) Improved calibration using newly calibrated Level $1 \mathrm{~b}$ Files (spectra) version 5 instead of version 4. Using the new Level $1 \mathrm{~b}$ product the solar zenith angle (SZA) dependent bias problem of $\mathrm{XCH}_{4} \mathrm{v} 0.5$ of several percent is significantly reduced (see also the discussion in Buchwitz et al., 2006a).

\subsection{Computation of column-averaged $\mathrm{CH}_{4}$ dry air mole fractions}

In contrast to carbon dioxide (Schneising et al., 2008a), this version of the WFM-DOAS data product of column-averaged methane dry air mole fractions uses simultaneously retrieved $\mathrm{CO}_{2}$ instead of $\mathrm{O}_{2}$ as a proxy for the air column because of better cancellation of path length related retrieval errors. This assumes that $\mathrm{CO}_{2}$ is significantly less variable than methane, and that the optical light paths for the two absorbers are, at least in first order, the same for the two spectral fitting windows which are located close to one another in SCIAMACHY channel 6 (Frankenberg et al., 2006). For WFM-DOAS version 1.0, the column-averaged mole fraction $\mathrm{XCH}_{4}$ is computed as follows:

$\mathrm{XCH}_{4}=\frac{\mathrm{CH}_{4}^{\mathrm{col}}}{\left(\mathrm{CO}_{2}^{\mathrm{col}} / \mathrm{CO}_{2}^{\mathrm{mf}}\right)}$,

where $\mathrm{CH}_{4}^{\text {col }}$ is the retrieved absolute methane column (in molecules $/ \mathrm{cm}^{2}$ ), $\mathrm{CO}_{2}^{\text {col }}$ is the retrieved absolute $\mathrm{CO}_{2}$ column (in molecules $/ \mathrm{cm}^{2}$ ), and $\mathrm{CO}_{2}^{\mathrm{mf}}$ is the assumed (columnaveraged) mole fraction of $\mathrm{CO}_{2}$ used to convert the $\mathrm{CO}_{2}$ column into a corresponding dry air column. For $\mathrm{CO}_{2}^{\mathrm{mf}}$ we use a constant value of $370 \mathrm{ppm}$. Therefore, normalizing with carbon dioxide introduces a small systematic error associated with the variation of the $\mathrm{CO}_{2}$ column-averaged dry air mole fractions. This can be improved to a certain extent using modeled $\mathrm{CO}_{2}^{\mathrm{mf}}$ fields, for example from the CarbonTracker assimilation system (Peters et al., 2007). A detailed discussion of the impact of assuming a constant carbon dioxide mole fraction follows later in Sect. 5. 


\subsection{Quality flags}

In order to separate out ground scenes affected by clouds or poor spectral fits, quality flags marking successful measurements are set for each single measurement (i.e., for each observed ground scene). It has to be pointed out that neither the spectral fitting method nor the quality filtering puts any constraints on the retrieved methane or carbon dioxide columns or mole fractions in the sense that the retrieved or accepted values are forced to lie in a pre-defined range of values.

For the column-averaged dry air mole fraction of methane, measurements satisfying the following criteria are classified as being good by the WFM-DOAS retrieval and are subsequently used for the analysis described in this manuscript:

- The root-mean-square (RMS) of the fit residuum (relative difference between measurement and model after the fit) in the $\mathrm{CH}_{4}$ fitting window has to be less than $0.4 \%$.

- The $\mathrm{CH}_{4}$ column fit error has to be less than $4 \%$.

- The RMS of the fit residuum in the $\mathrm{CO}_{2}$ fitting window has to be less than $0.25 \%$.

- The $\mathrm{CO}_{2}$ column fit error has to be less than $2.5 \%$.

- The observed scene has to be nearly cloud free, as defined by a retrieved $\mathrm{O}_{2}$ column larger than $90 \%$ of the assumed a-priori $\mathrm{O}_{2}$ column (determined from surface elevation and the known mixing ratio of $\mathrm{O}_{2}$ ) and a RMS of the fit residuum in the $\mathrm{O}_{2}$ fitting window less than $2 \%$.

- The SZA has to be less than $75^{\circ}$ (as the signal gets weaker for high SZAs and the sensitivity to changes of the absorber amount in the boundary layer decreases with increasing SZA).

- The ground pixel must be a forward scan pixel (as the horizontal resolution of the backward scan pixel is four times larger (typically $240 \mathrm{~km}$ across track compared to $60 \mathrm{~km}$ for the forward scan)).

In case of normalizing methane with oxygen, which has been done additionally for the purpose of comparison and to discuss to what extent the SCIAMACHY methane product is influenced by $\mathrm{CO}_{2}$ (see Sect. 5), an aerosol filter based on the Earth Probe/TOMS absorbing aerosol index (Herman et al., 1997 ) is added (Schneising et al., 2008a), only ground pixels over land are considered, and the identification of cloud contaminated ground scenes is supplemented by the additional threshold algorithm based on sub-pixel information provided by the SCIAMACHY Polarization Measurement Device (PMD) channel 1 detecting enhanced backscatter in the UV (Buchwitz et al., 2005a).
Table 1. Results of the error analysis for different albedos performed by applying WFM-DOAS to simulated SCIAMACHY spectra. The results are valid for a solar zenith angle of $50^{\circ}$ and a surface elevation corresponding to sea level.

\begin{tabular}{crrr}
\hline Albedo & $\begin{array}{r}\mathrm{CH}_{4} \text { column } \\
\text { error [\%] }\end{array}$ & $\begin{array}{r}\mathrm{CO}_{2} \text { column } \\
\text { error [\%] }\end{array}$ & $\begin{array}{r}\mathrm{XCH}_{4} \\
\text { error [\%] }\end{array}$ \\
\hline 0.003 & 0.59 & 0.63 & -0.04 \\
0.03 & 0.03 & -0.01 & 0.04 \\
0.05 & -0.01 & -0.05 & 0.04 \\
0.08 & 0.00 & -0.04 & 0.04 \\
0.10 & 0.03 & -0.01 & 0.04 \\
0.15 & -0.07 & -0.13 & 0.06 \\
0.20 & -0.08 & -0.13 & 0.05 \\
0.30 & 0.02 & -0.01 & 0.03 \\
0.40 & 0.18 & 0.18 & 0.00 \\
\hline
\end{tabular}

\section{Error analysis}

The retrieved methane and carbon dioxide vertical columns exhibit a random error due to instrument noise depending on the signal-to-noise ratio of the spectral measurements and thus on surface albedo, solar zenith angle, and characteristics of the detector. Taking into account the different detector materials in channel 6 below $1590 \mathrm{~nm}$, where the $\mathrm{CO}_{2}$ fitting window is mainly located, and above $1590 \mathrm{~nm}$ (the so called channel 6+), where the $\mathrm{CH}_{4}$ fitting window is located, results in theoretical random errors of $0.7 \%$ of the retrieved $\mathrm{CO}_{2}$ column and $1.5 \%$ of the retrieved $\mathrm{CH}_{4}$ column for a typical surface albedo of land of about 0.2 and a solar zenith angle of $50^{\circ}$. Therefore, the theoretical $\mathrm{XCH}_{4}$ single ground pixel retrieval precision due to instrument noise can be estimated to be about $1.7 \%$ on average.

To estimate the single ground pixel retrieval precision of the real in-orbit measurements we determined for several locations daily standard deviations of the retrieved $\mathrm{XCH}_{4}$ (because of the orbit geometry this basically corresponds to the standard deviation of all the data from a single overpass at around 10:00 a.m. local time). We averaged the daily standard deviations determined from all the SCIAMACHY $\mathrm{XCH}_{4}$ retrievals at a given location for all days where at least 10 measurements pass the quality filter in a radius of $350 \mathrm{~km}$ around that location. This average $\mathrm{XCH}_{4}$ standard deviation can be interpreted as an upper limit of the single ground pixel retrieval precision (as it is also influenced by atmospheric methane variability). This analysis was performed for Park Falls (Wisconsin, USA), Bremen (northern Germany), and Darwin (northern Australia) providing a consistent estimate of the precision error of about 25-30 ppb, respectively, which corresponds approximately to $1.5-1.7 \%$, in good agreement with the theoretical estimate of $1.7 \%$ given above.

In addition to instrument noise there are several other error sources such as errors resulting from the variability of 
Table 2. As Table 1 but for the spectral albedos of natural surfaces taken from the ASTER and USGS spectral libraries (see Schneising et al., 2008a).

\begin{tabular}{lrrrrr}
\hline Surface type & $\begin{array}{r}\mathrm{CH}_{4} \text { column } \\
\text { error [\%] }\end{array}$ & $\begin{array}{r}\mathrm{CO}_{2} \text { column } \\
\text { error [\%] }\end{array}$ & $\begin{array}{r}\mathrm{O}_{2} \text { column } \\
\text { error [\%] }\end{array}$ & $\begin{array}{r}\mathrm{XCH}_{4} \\
\text { error [\%] }\end{array}$ & $\begin{array}{r}\mathrm{XCH}_{4}\left(\mathrm{O}_{2}\right) \\
\text { error [\%] }\end{array}$ \\
\hline Sand (Entisol) & 0.23 & 0.13 & 0.03 & 0.10 & 0.20 \\
Soil (Mollisol) & 0.37 & 0.41 & 0.13 & -0.04 & 0.24 \\
Deciduous (Aspen) & -0.01 & 0.22 & 0.17 & -0.23 & -0.18 \\
Conifers-Meadow & 0.04 & -0.01 & 0.11 & 0.05 & -0.07 \\
Rangeland & 0.04 & -0.11 & -0.04 & 0.15 & 0.08 \\
Open Ocean & 0.09 & 0.06 & 0.16 & 0.03 & -0.07 \\
Medium Snow & 0.65 & 0.37 & 1.83 & 0.28 & -1.16 \\
\hline
\end{tabular}

Table 3. Aerosol scattering (ASOD) and aerosol absorption vertical optical depth (AAOD) in the $\mathrm{O}_{2}, \mathrm{CO}_{2}$, and $\mathrm{CH}_{4}$ fitting windows for the aerosol scenarios used in the error analysis. For comparison the Rayleigh scattering vertical optical depth (RSOD) has also been included. The default values used for the WFM-DOAS look-up table (LUT) are given in the first two rows.

\begin{tabular}{lllll}
\hline Aerosol scenario & & $756 \mathrm{~nm}$ & $1560 \mathrm{~nm}$ & $1630 \mathrm{~nm}$ \\
\hline LUT default & ASOD: & 0.24669 & 0.17369 & 0.16981 \\
& AAOD: & 0.00291 & 0.00307 & 0.00313 \\
OPAC background & ASOD: & 0.09353 & 0.02211 & 0.01977 \\
& AAOD: & 0.00315 & 0.00293 & 0.00262 \\
OPAC urban & ASOD: & 0.16420 & 0.04794 & 0.04414 \\
& AAOD: & 0.02373 & 0.01411 & 0.01324 \\
OPAC desert & ASOD: & 0.22740 & 0.17568 & 0.16852 \\
\multirow{3}{*}{ Extreme in BL } & AAOD: & 0.01406 & 0.00419 & 0.00402 \\
& ASOD: & 2.12661 & 0.91676 & 0.87507 \\
& AAOD: & 0.13324 & 0.07892 & 0.07829 \\
\hline \multirow{5}{*}{} & RSOD: & 0.02674 & 0.00145 & 0.00122 \\
\hline
\end{tabular}

temperature and water vapour profiles, aerosols, clouds, and albedo. These errors were already quantified for earlier versions of WFM-DOAS (Buchwitz and Burrows, 2004; Buchwitz et al., 2005a). Because of the improved albedo treatment in version 1.0, with albedo retrieval and the extended look-up table interpolation/extrapolation method, the albedo related $\mathrm{XCH}_{4}$ errors shown in Table 1, which could be as large as about $1 \%$ in the previous version, are now significantly reduced and negligible (absolute value less than $0.1 \%$ ) for typical (but within a given small spectral fitting window wavelength independent) albedos. Table 2 shows the retrieval errors for different natural surface types taking the full spectral albedo dependence into account. As can be seen, the errors estimated from the simulated retrievals are well below $1 \%$ for typical surfaces. Normalizing methane with $\mathrm{O}_{2}$ leads to a somewhat larger error in the case of snow because the very high albedo in the $\mathrm{O}_{2}$ fitting window considerably exceeds 0.3 (the highest value in the reference spectra look-up table LUT).
The $\mathrm{XCH}_{4}$ retrieval error due to surface elevation (or mean surface pressure) changes is also considerably reduced due to the better consideration of surface elevation changes dropping for example from $1.0 \%$ in version 0.5 for a surface elevation of $400 \mathrm{~m}$ (Buchwitz et al., 2005a) to $0.1 \%$ in version 1.0 by using the new altitude interpolation/extrapolation scheme.

To estimate the retrieval error due to aerosols several aerosol scenarios have been defined (see Tables 3 and 4). The default scenario used for the LUT can be characterized as follows: Maritime aerosol in the boundary layer (BL), tropospheric visibility and humidity $23 \mathrm{~km}$ and $80 \%$, respectively, background stratospheric, and normal mesospheric conditions. Besides the rather extreme scenario with strongly enhanced aerosol in the boundary layer (urban aerosol in the BL with visibility of only $2 \mathrm{~km}$ and relative humidity of $99 \%$ ), three additional more typical scenarios are considered (using Mie phase function instead of the Henyey-Greenstein parameterization used for the LUT default scenario): (i) "OPAC background" consists of continental relatively clean aerosol in the BL and the free troposphere $(99.998 \%$ water soluble), (ii) "OPAC urban" has continental polluted aerosol in the boundary layer ( $31.399 \%$ water soluble and $68.6 \%$ soot) and continental average aerosol $(45.79 \%$ water soluble and $54.2 \%$ soot) in the free troposphere, and (iii) "OPAC desert" consists of desert aerosol (93.19\% mineral nucleation mode and $6.81 \%$ mineral accumulation mode) in the boundary layer and the continental clean aerosol type in the free troposphere. For all scenarios the $\mathrm{XCH}_{4}$ error due to aerosols is considerably less than $1 \%$ even for the extreme one. When normalizing methane with oxygen, however, this error can be as high as about $6 \%$ in extreme situations because the sensitivity in the $\mathrm{O}_{2}$ A-band is significantly larger than in the NIR in these cases; hence strongly aerosol contaminated scenes have to be filtered out as described in Schneising et al. (2008a) when using $\mathrm{O}_{2}$ to normalize the greenhouse gas columns. 
Table 4. Results of the error analysis for various aerosol scenarios. The results are valid for an albedo of 0.1 , a solar zenith angle of $50^{\circ}$, and a surface elevation corresponding to sea level.

\begin{tabular}{lrrrrr}
\hline Aerosol scenario & $\begin{array}{r}\mathrm{CH}_{4} \text { column } \\
\text { error [\%] }\end{array}$ & $\begin{array}{r}\mathrm{CO}_{2} \text { column } \\
\text { error [\%] }\end{array}$ & $\begin{array}{r}\mathrm{O}_{2} \text { column } \\
\text { error [\%] }\end{array}$ & $\begin{array}{r}\mathrm{XCH}_{4} \\
\text { error [\%] }\end{array}$ & $\begin{array}{r}\mathrm{XCH}_{4}\left(\mathrm{O}_{2}\right) \\
\text { error [\%] }\end{array}$ \\
\hline OPAC background & -0.60 & -0.73 & 0.26 & 0.13 & -0.86 \\
OPAC urban & -0.57 & -0.70 & -0.05 & 0.13 & -0.52 \\
OPAC desert & -0.08 & -0.14 & -0.49 & 0.06 & 0.41 \\
Extreme in BL & -0.89 & -1.16 & -6.50 & 0.27 & 6.00 \\
\hline
\end{tabular}

Table 5. Retrieval errors resulting from applying WFM-DOAS to various model atmospheres valid for an albedo of 0.1 , a solar zenith angle of $50^{\circ}$, and a surface elevation corresponding to sea level. The analysed atmospheres differ from the US Standard Atmosphere used as reference with respect to temperature, pressure, water vapour and methane profiles.

\begin{tabular}{lrrrrr}
\hline Atmosphere & $\begin{array}{r}\mathrm{CH}_{4} \text { column } \\
\text { error [\%] }\end{array}$ & $\begin{array}{r}\mathrm{CO}_{2} \text { column } \\
\text { error [\%] }\end{array}$ & $\begin{array}{r}\mathrm{O}_{2} \text { column } \\
\text { error [\%] }\end{array}$ & $\begin{array}{r}\mathrm{XCH}_{4} \\
\text { error [\%] }\end{array}$ & $\begin{array}{r}\mathrm{XCH}_{4}\left(\mathrm{O}_{2}\right) \\
\text { error [\%] }\end{array}$ \\
\hline Sub-artic summer & 1.18 & 0.04 & -0.38 & 1.14 & 1.57 \\
Sub-artic winter & 1.30 & 0.17 & 0.67 & 1.13 & 0.63 \\
Mid-latitude summer & 0.99 & -0.15 & -0.55 & 1.14 & 1.55 \\
Mid-latitude winter & 1.25 & 0.47 & 0.66 & 0.78 & 0.59 \\
Tropical & 0.34 & -0.54 & -0.68 & 0.88 & 1.03 \\
\hline
\end{tabular}

In order to examine the sensitivity to vertical profile variations of temperature, pressure, and trace gases, simulated spectra for several model atmospheres (extracted from MODTRAN; Berk et al., 1998) have been generated while the WFM-DOAS look-up table is based on the US Standard Atmosphere. The analysed atmospheres differ from the US Standard Atmosphere with respect to temperature, pressure, water vapour and methane profiles. The resulting retrieval errors are shown in Table 5.

The error analysis shows that the sensitivity to most of the considered parameters influencing the radiative transfer is smaller when normalizing methane with carbon dioxide instead of oxygen because of the much smaller spectral distance of the $\mathrm{CH}_{4}$ and $\mathrm{CO}_{2}$ fitting windows and, therefore, better cancellation of errors. Hence, the $\mathrm{O}_{2}$-normalized methane product is only used for comparison and to draw qualitative conclusions. The error analysis also shows that the $\mathrm{XCH}_{4}$ obtained using $\mathrm{CO}_{2}$ has smaller relative errors than the absolute methane columns due to cancellation of errors. Using (assumed error free) surface pressure information from meteorological analysis to convert the measured methane columns to $\mathrm{XCH}_{4}$, the relative $\mathrm{XCH}_{4}$ errors would be (nearly) identical as the relative errors of the $\mathrm{CH}_{4}$ columns. Therefore estimating the air column using simultaneously measured $\mathrm{CO}_{2}$ typically results in a higher quality $\mathrm{XCH}_{4}$ than using, for example, meteorological surface pressure.

\section{Discussion of the multi-year $\mathrm{XCH}_{4}$ data set}

All available SCIAMACHY spectra (Level 1b version 5 converted to Level 1c using the standard calibration) for the years 2003, 2004, and 2005 have been processed using the improved retrieval algorithm WFM-DOAS version 1.0. The resulting annual composite averages for $\mathrm{XCH}_{4}$, which meet the classification "good" defined above, are shown in Fig. 1.

Significant features which are apparent in the $\mathrm{XCH}_{4}$ fields of all three years are a clearly visible interhemispheric gradient and significantly enhanced $\mathrm{XCH}_{4}$ over known methane source regions such as South-East Asia (e.g., wetlands, rice paddies, ruminants) and large parts of Russia and tropical South America and Africa (e.g., wetlands).

A comparison of the SCIAMACHY WFM-DOAS version 1.0 methane product with European Fourier Transform Spectrometers (FTS) located at seven ground stations has been performed by Dils et al. (2006b) for the years 2003 and 2004 showing reasonable to good agreement between the two data sets. The standard deviation of the difference between the data sets is about $1.5 \%$. The latter includes the error of the SCIAMACHY measurements, the FTS measurement error, and the error of the comparison method. In addition, a small constant bias of SCIAMACHY of about 2-3\% has been identified as compared to the FTS measurements. Biases need to be minimized as much as possible when the data are going to be used for inverse modelling of methane sources and sinks. Constant (or nearly constant) biases can be relatively 


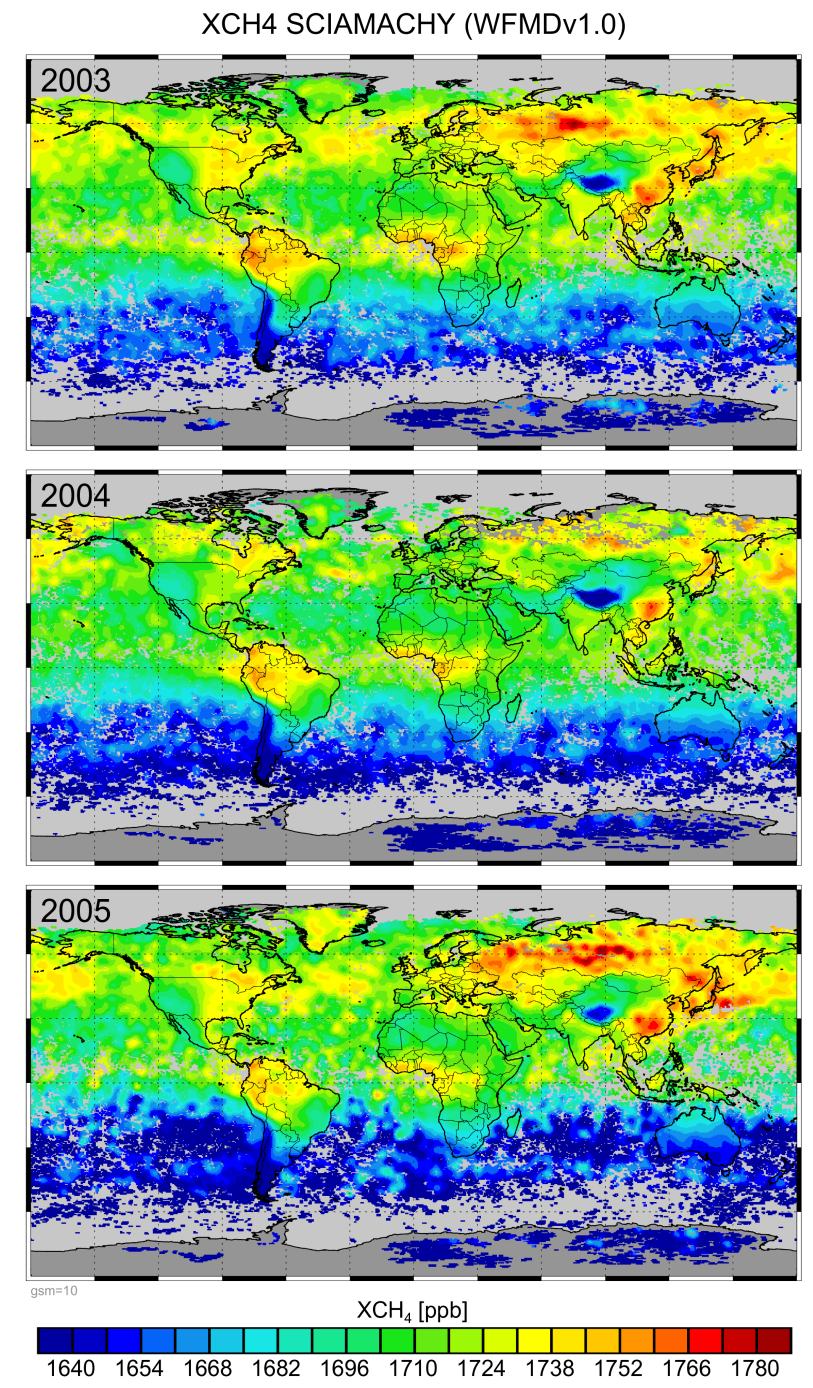

Fig. 1. Three years of SCIAMACHY methane column-averaged dry air mole fractions as retrieved by WFM-DOAS version 1.0 (WFMDv1.0). Shown are yearly averages for 2003 (top), 2004 (middle), and 2005 (bottom).

easy corrected for in coupled inversions including also surface measurements as high-accuracy reference (Bergamaschi et al., 2007).

To assess the quality of the global data we have performed a comparison with $\mathrm{CH}_{4}$ model simulations, based on the TM5 model which has been optimized versus highly accurate surface methane measurements from the NOAA/ESRL network (Bergamaschi et al., 2007). The TM5 model (Krol et al., 2005) is a two-way nested atmospheric zoom model using off-line transport based on ECMWF meteorological fields. The tropospheric standard version of TM5 with 25 vertical layers has been used in this study. While the inversion has been performed using the $6^{\circ} \times 4^{\circ}$ coarse resolution, the model has been rerun with the optimized emissions at global resolution of $3^{\circ} \times 2^{\circ}$, and 6 embedded zoom regions over major continental areas (North America, South America, Europe, Africa, Asia, and Australia), simulated with high resolution of $1^{\circ} \times 1^{\circ}$. We use the Scenario S1 of Bergamaschi et al. (2007) based on the surface measurements from the NOAA network and the new wetland inventory of J. O. Kaplan (European Commission's Joint Research Centre). To account for small differences in the altitude sensitivity of the SCIAMACHY measurements we have applied the SCIAMACHY averaging kernels to the TM5 model output when computing the column-averaged methane mole fraction:

$$
\mathrm{XCH}_{4}^{\mathrm{mod}}=\frac{1}{p_{0}} \sum_{l}\left(\overline{\mathrm{XCH}}_{4}^{l}+A K^{l}\left(\mathrm{XCH}_{4}^{\bmod }{ }^{l}-\overline{\mathrm{XCH}}_{4}^{l}\right)\right) \Delta p^{l}
$$

where $l$ is the index of the vertical layer, $A K^{l}$ the averaging kernel, $\overline{\mathrm{XCH}}_{4}^{l}$ the a-priori mole fraction (1750 ppb below $6 \mathrm{~km}$, profile available from the WFM-DOAS web site) and $\mathrm{XCH}_{4}^{\text {mod }}{ }^{l}$ the simulated mole fraction of layer $l . \Delta p^{l}$ is the pressure difference between the upper and lower boundary of layer $l$ and $p_{0}$ denotes surface pressure.

The comparison with the TM5 model is performed for

(a) the year 2003 global average in Fig. 2,

(b) seasonal global averages in Fig. 4 ,

(c) selected regions and seasonal averages in Figs. 5-7,

(d) latitudinal averages in Fig. 8, and

(e) regional time series in Fig. 10 with the corresponding regions shown in Fig. 9.

As can be seen, agreement is typically within 1-2\% (approximately $17-34 \mathrm{ppb}$ ) with the exception of large parts of the tropics where significantly higher $\mathrm{XCH}_{4}$ is observed as compared to the model. This is qualitatively consistent with the finding of higher column-averaged $\mathrm{CH}_{4}$ mole fractions over tropical regions detected by the independent retrieval algorithm of Frankenberg et al. (2005b, 2006), compared to the inverse model simulations of scenario S1 in Bergamaschi et al. (2007), suggesting higher tropical emissions than assumed by TM5 which is also supported by independent aircraft measurements over the Amazon basin (Miller et al., 2007). However, the high methane levels over the tropics are now considered to be lower than initially retrieved due to a recent update in the near-infrared water vapour spectroscopy (Frankenberg et al., 2008b). The impact of the new spectroscopic data on the WFM-DOAS retrievals, particularly with regard to the retrieved magnitude of the tropical enhancement, agreement with model simulations, and quality of the fits, is discussed in Sect. 6.

It has been suggested that the high tropical methane observed by SCIAMACHY may be due to emissions from living plants (Keppler et al., 2006). However, the potential role of plants has become now further controversial after a recent study by Dueck et al. (2007) questioning the measurements of Keppler et al. (2006). Using an independent method 


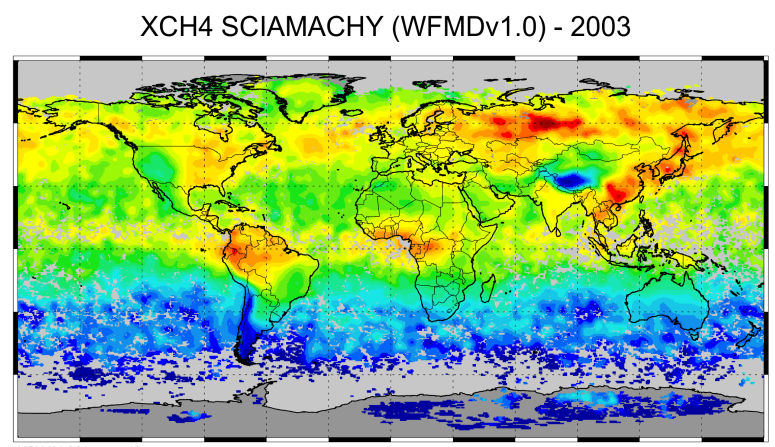

XCH4 TM5/JRC (Scenario S1) - 2003

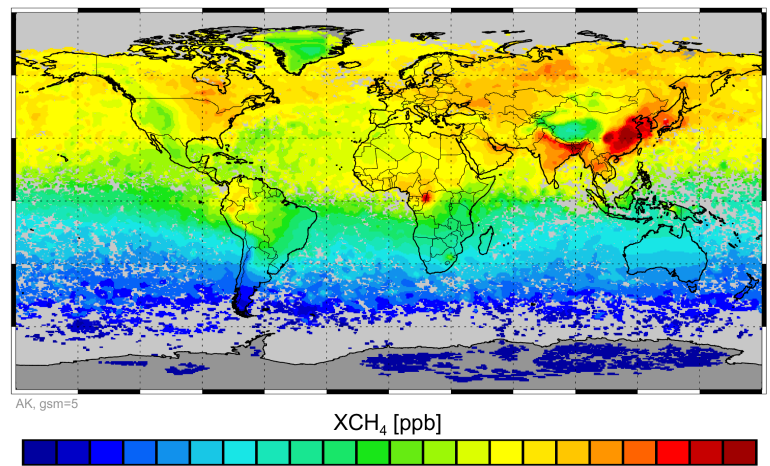

$\begin{array}{llllllllllll}1670 & 1684 & 1698 & 1712 & 1726 & 1740 & 1754 & 1768 & 1782 & 1796 & 1810\end{array}$ XCH4 SCIAMACHY (WFMDv1.0) - TM5/JRC

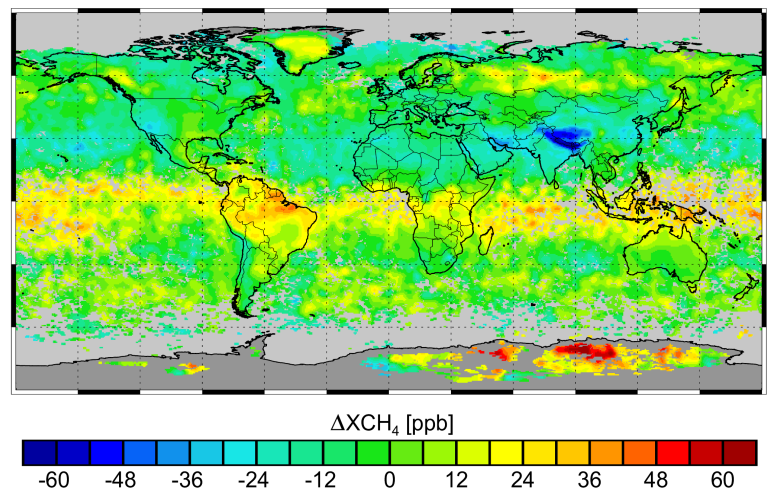

Fig. 2. Comparison of SCIAMACHY/WFMDv1.0 $\mathrm{XCH}_{4}$ (top) with TM5 model simulations (middle) for the year 2003. The SCIAMACHY data have been scaled with 1.02 to compensate for a systematic offset between the two data sets. The TM5 model data have been sampled in time and space as the SCIAMACHY instrument measures and the SCIAMACHY averaging kernels have been applied to TM5. The bottom panel shows the difference between SCIAMACHY and TM5.

based on ${ }^{13} \mathrm{C}$ labelling and laser-based measurements, Dueck et al. (2007) did not find evidence for substantial $\mathrm{CH}_{4}$ emissions of plants under aerobic conditions while Keppler et al. (2008) confirm their earlier work by providing evidence that methoxyl groups of pectin can act as a source of atmospheric $\mathrm{CH}_{4}$ under aerobic conditions. Nevertheless, the contribution of emissions from plants to the global methane budget remains uncertain.

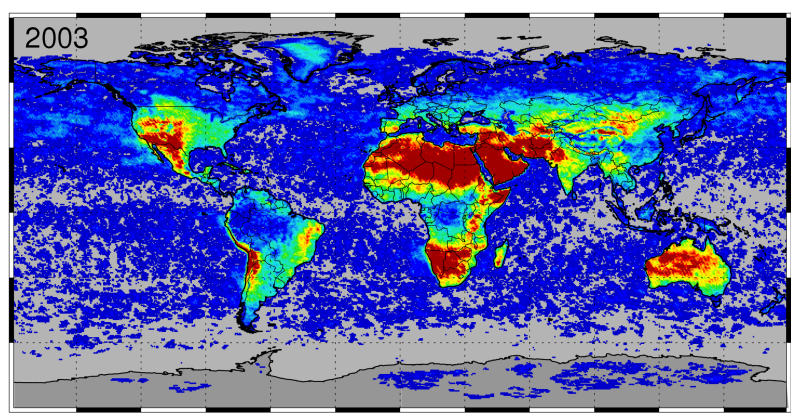

$\mathrm{N}[-]$

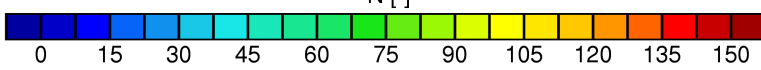

XCH4 SCIAMACHY (XCO2 constant) - 2003

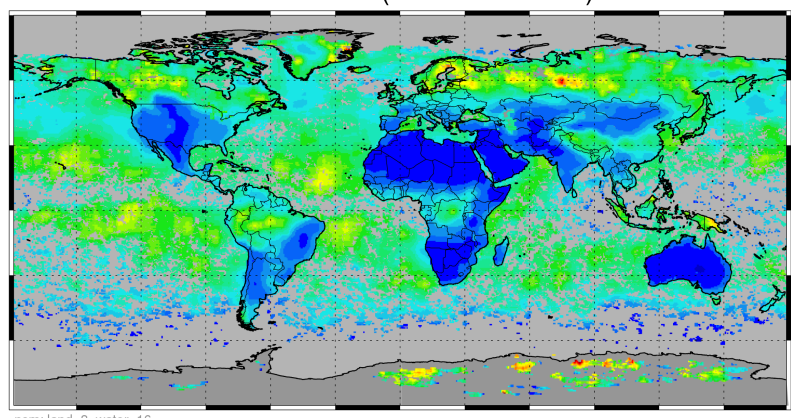

XCH4 SCIAMACHY (XCO2 CarbonTracker) - 2003

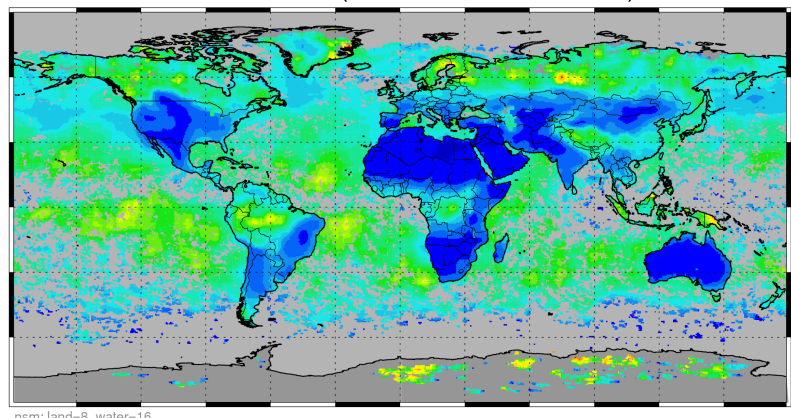

Estimated statistical error [\%]

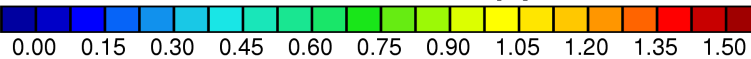

Fig. 3. Estimated statistical error associated with the WFM-DOAS retrieval obtained by averaging the relative standard deviation of the difference SCIA-TM5 over all $N$ available annual retrievals for each grid cell ( $N$ is shown in the top panel) via division by $\sqrt{N}$ (middle panel without $\mathrm{CO}_{2}$ correction; bottom panel with $\mathrm{CO}_{2}$ correction). By comparison with Fig. 2 of Schneising et al. (2008a) one observes an anti-correlation with the retrieved near-infrared albedo because the number of measurements classified good increases with albedo due to a better signal-to-noise ratio of the spectra.

Although $\mathrm{CO}_{2}$ is less variable than $\mathrm{CH}_{4}$ it is not constant and therefore variations in $\mathrm{CO}_{2}$, especially its seasonal cycle, introduce a small error in the retrieved $\mathrm{XCH}_{4}$. This can be taken into account by considering modeled column-averaged mole fractions of $\mathrm{CO}_{2}$ instead of assuming a globally constant mole fraction when computing $\mathrm{XCH}_{4}$, i.e., by using 

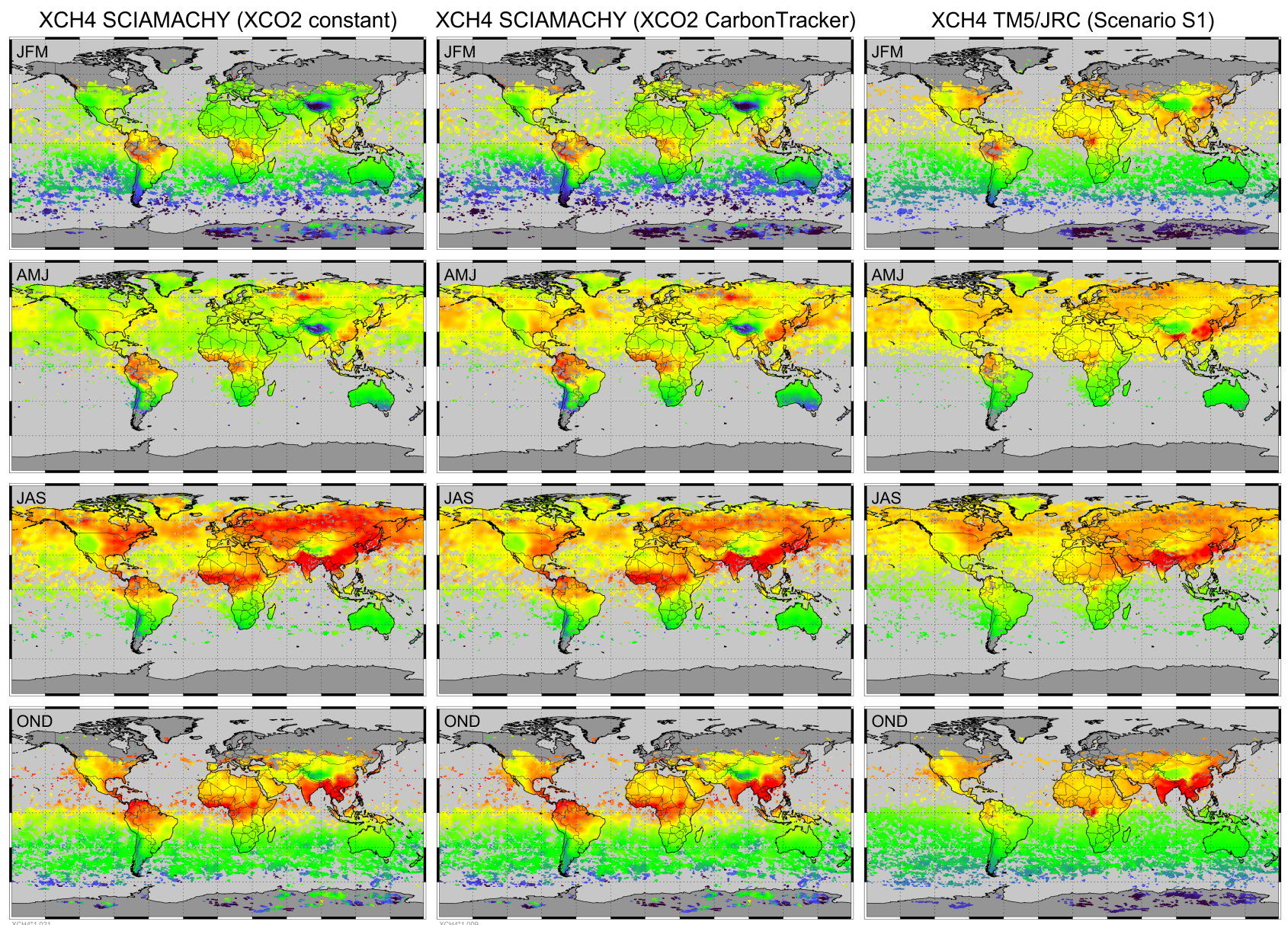

$\mathrm{XCH}_{4}[\mathrm{ppb}]$

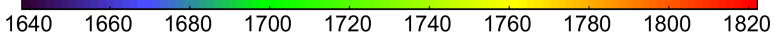

Fig. 4. Seasonal averages for the year 2003 of measured and modeled methane (from top to bottom: January-March (JFM), April-June (AMJ), July-September (JAS), and October-December (OND) seasons). The first column shows the WFMDv1.0 methane based on using a constant mole fraction of $\mathrm{CO}_{2}$ for the $\mathrm{XCH}_{4}$ computation. The second column shows SCIAMACHY methane obtained using $\mathrm{XCO}_{2}$ from the CarbonTracker assimilation system. The last column shows modeled TM5 methane.

modeled $\mathrm{CO}_{2}^{\mathrm{mf}}$ in Eq. (3) instead of a constant value. This approach has been introduced by Frankenberg et al. (2006). This ideally requires that the $\mathrm{CO}_{2}$ distribution is well known everywhere, which is not the case. The effect of using modeled $\mathrm{CO}_{2}$ variations using the CarbonTracker assimilation system is depicted in Figs. 3-10 (here modeled $\mathrm{CO}_{2}^{\mathrm{mf}}$ is the column-averaged mole fraction of $\mathrm{CO}_{2}$, i.e., $\mathrm{XCO}_{2}$, obtained from the CarbonTracker $\mathrm{CO}_{2}$ mixing ratio vertical profiles computed taking the SCIAMACHY $\mathrm{CO}_{2}$ averaging kernels into account).

Similar to the inverse $\mathrm{CH}_{4}$ model simulations used here, the CarbonTracker $\mathrm{CO}_{2}$ simulations are optimized versus the highly accurate but sparse surface $\mathrm{CO}_{2}$ observations from the NOAA/ESRL network. The CarbonTracker $\mathrm{CO}_{2}$ fields are available from http://www.esrl.noaa.gov/gmd/ ccgg/carbontracker/. CarbonTracker is also based on the transport model TM5 but a different inversion technique has been used to optimize the model with respect to the surface measurements. While the $\mathrm{CH}_{4}$ inversion is based on the synthesis inversion technique, CarbonTracker uses an Ensemble Kalman Filter assimilation technique. As for the (inverse) modeled $\mathrm{CH}_{4}$, the SCIAMACHY averaging kernels were applied to the CarbonTracker $\mathrm{CO}_{2}$ vertical profiles to take the SCIAMACHY altitude sensitivity into account.

The global average of the standard deviation of the difference of retrieved and modeled column-averaged methane mole fractions, which is $1.7 \%$ when correcting for $\mathrm{CO}_{2}$ variability by the usage of assimilated CarbonTracker mole fractions $\left(1.8 \%\right.$ when assuming constant $\left.\mathrm{CO}_{2}\right)$ is consistent with the single ground scene $\mathrm{XCH}_{4}$ retrieval precision error of SCIAMACHY derived in Sect. 4. Averaging over $N$ independent retrievals reduces the random error and the resulting 


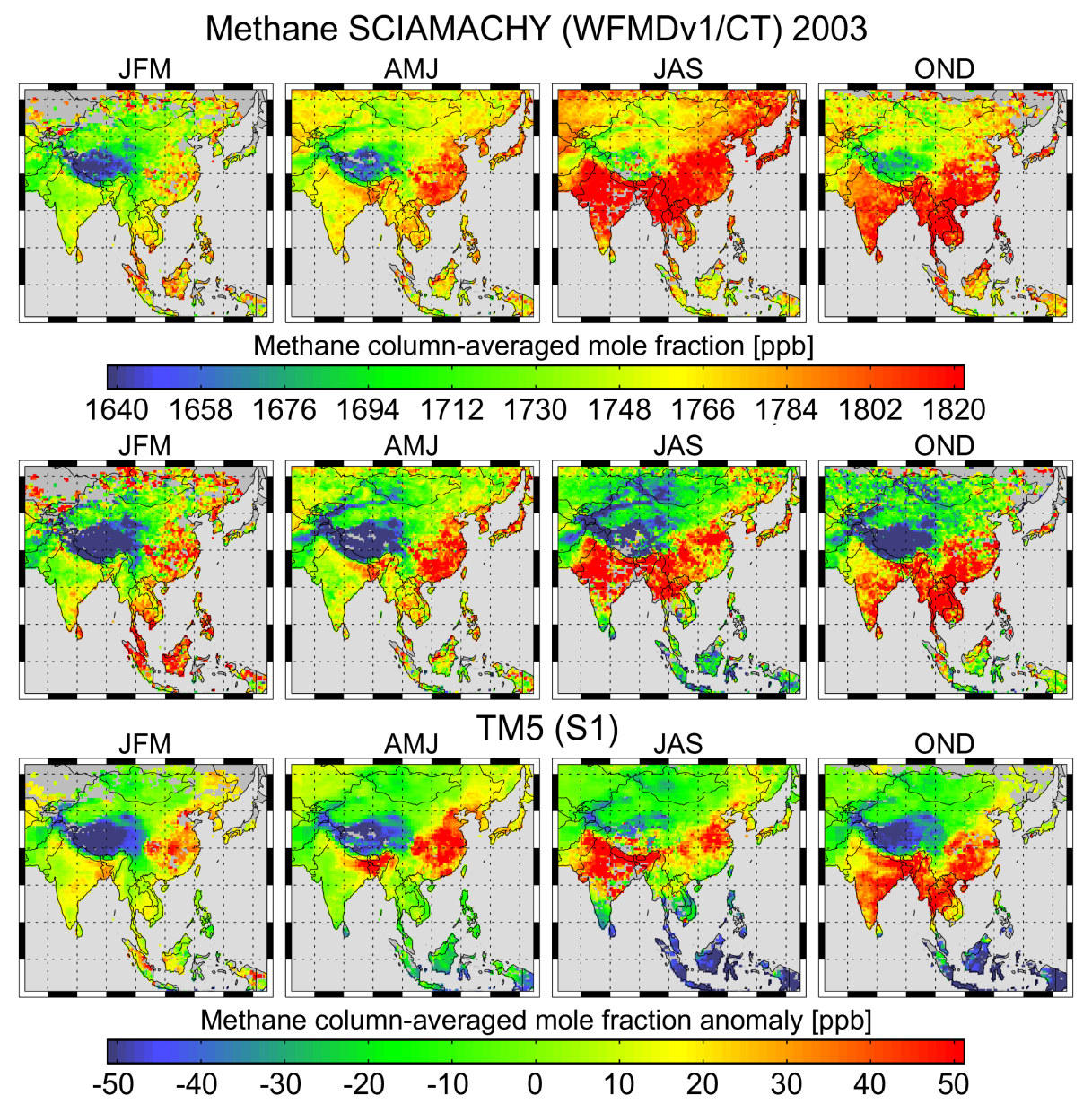

Fig. 5. Comparison of seasonal $\mathrm{XCH}_{4}$ averages over South-East Asia between SCIAMACHY (top) and TM5 (bottom). To better highlight the spatial pattern the data are shown as anomalies, i.e., the mean value has been subtracted for each map separately. The (unscaled) SCIAMACHY XCH 4 has been corrected for $\mathrm{CO}_{2}$ variations using CarbonTracker. The SCIAMACHY data have been gridded on a $0.5^{\circ} \times 0.5^{\circ}$ latitude/longitude grid and TM5 has been sampled as SCIAMACHY measures using the same grid. The SCIAMACHY methane averaging kernels have been applied to TM5. Shown are tri-monthly averages for the year 2003 (from left to right: January-March (JFM), April-June (AMJ), July-September (JAS), and October-December (OND)).

estimated relative statistical error, which is calculated by division by $\sqrt{N}$, is shown in Fig. 3 .

Additionally the observed quite systematic low bias of the WFM-DOAS data drops from $2 \%$ to $1 \%$ when using CarbonTracker $\mathrm{XCO}_{2}$ to estimate the dry air column. It can be seen that for most seasons and most regions the difference (after accounting for this bias by appropriate scaling) when using a constant and the model $\mathrm{CO}_{2}$ are small but may reach about $1 \%$ in the Northern Hemisphere in spring time locally when the expected $\mathrm{CO}_{2}$ seasonal cycle has its maximum. Figures 4, 8, and 10 show that the disregard of the seasonal variations of $\mathrm{CO}_{2}$ may result in higher retrieved seasonal methane variations than in the CarbonTracker-corrected data product. This effect is in particular observable over Northern Hemisphere mid-latitudes where the impact of the $\mathrm{CO}_{2}$ correction can be as large as about $30 \mathrm{ppb}$ when comparing summer to spring $\mathrm{XCH}_{4}$ changes (see AMJ and JAS sea- sons in Fig. 8). Figure 8 additionally shows that the usage of modeled $\mathrm{CO}_{2}$ variability reduces an elsewise existent seasonal latitudinal bias compared to TM5. Hence, it can be concluded that taking the modeled $\mathrm{CO}_{2}$ variations into account in the $\mathrm{XCH}_{4}$ product generally results in a better agreement with the methane model and is therefore better suited for quantitative examinations or inverse modeling. Assuming a constant $\mathrm{CO}_{2}$ would also introduce a superposed decreasing methane trend when studying the methane evolution over longer time periods due to increasing atmospheric $\mathrm{CO}_{2}$ concentrations (Buchwitz et al., 2007; IPCC, 2001, 2007).

As shown in Fig. 4, major methane source regions are South-East Asia, in particular China and India, central Africa, and the northern part of South Amercia. Figures 5-7 show a comparison between seasonal averages of the SCIAMACHY and TM5 $\mathrm{XCH}_{4}$ for these three source regions. In order to focus on the spatial pattern of methane the data 


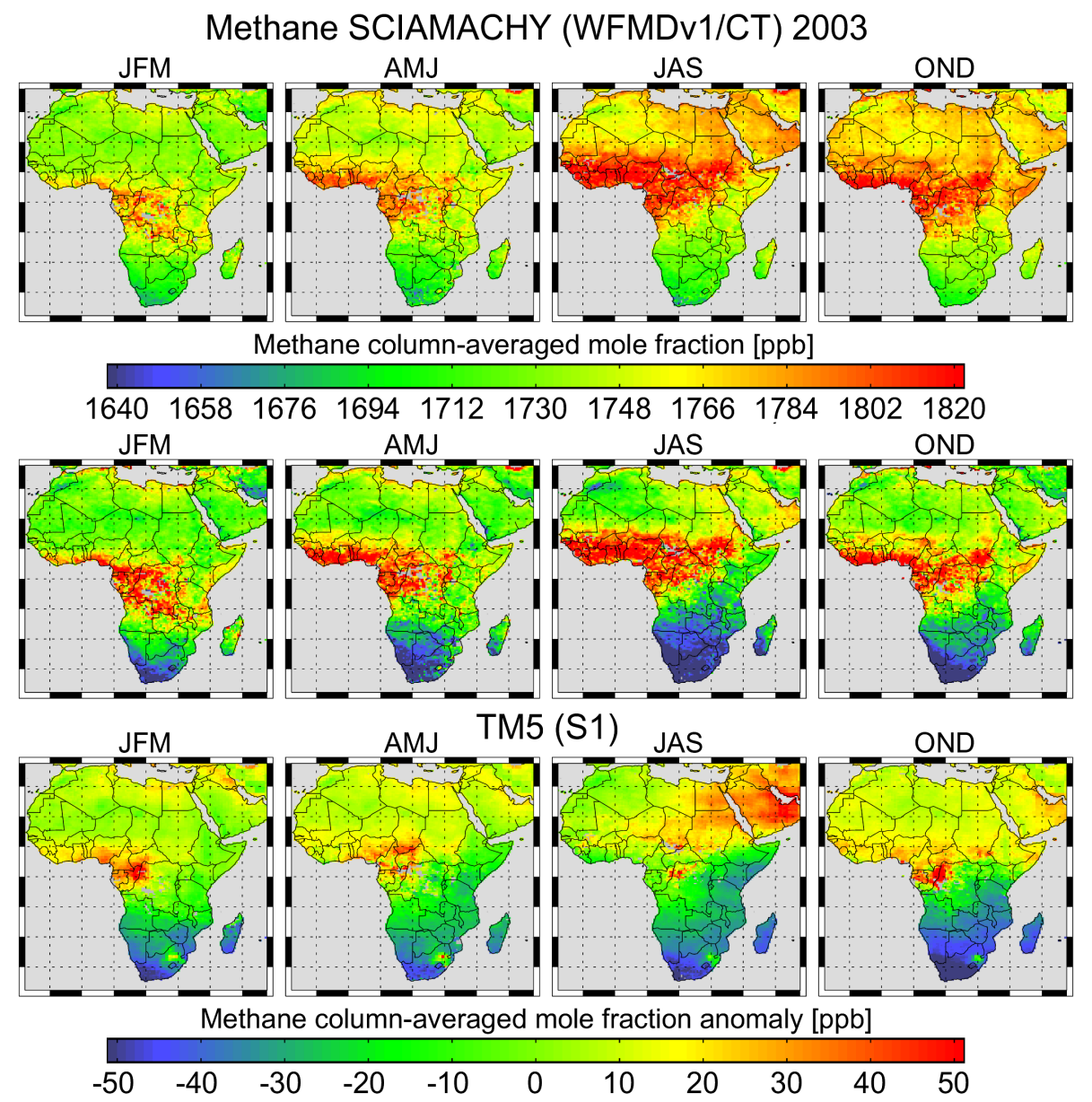

Fig. 6. As Fig. 5 but for Africa.

are shown as anomalies, i.e., the mean value has been subtracted for each map separately. Comparisons for these regions are also shown in Bergamaschi et al. (2007) for SCIAMACHY methane retrieved with the IMAP-DOAS algorithm (Frankenberg et al., 2006) and TM5. The comparison of the results shown here with the results shown in Bergamaschi et al. (2007) reveals that the differences between the two independent SCIAMACHY methane data products (obtained with WFM-DOAS (WFMD) and IMAP-DOAS (IMAP)) are quite similar but not exactly identical. If one compares, for example, Fig. 5 with Fig. 7 of Bergamaschi et al., 2007 one can see that both data products show the highest methane over India and China in the second half of 2003 around July-September with only slightly elevated methane during January-March (see also the time series for South-East Asia shown in Fig. 10). Major methane sources in this region are rice paddies, wetlands, and ruminants (for a detailed discussion see Bergamaschi et al., 2007). Concerning the details of the spatial pattern there are however also differences resulting from the different retrieval algorithms and the different quality filtering applied to the data prior to averaging. The SCIAMACHY/IMAP methane shows, for example, lower methane over large parts of India and China during October-December relative to July-September whereas TM5 still shows relatively high methane also during October-December. In contrast, the SCIAMACHY/WFMD methane shown in Fig. 5 agrees with TM5 reasonably well also during October-December.

Similar conclusions, namely that the two SCIAMACHY methane data products are similar but not exactly identical, can be drawn for other regions, e.g., Africa shown in Fig. 6, to be compared with Fig. 9 of Bergamaschi et al. (2007), and South America shown in Fig. 7, to be compared with Fig. 8a of Bergamaschi et al. (2007). These figures show that despite the fact that both methane data products, SCIAMACHY/WFMD and SCIAMACHY/IMAP, are not exactly identical, higher tropical methane is retrieved from SCIAMACHY compared to TM5.

Concerning the higher tropical methane retrieved from SCIAMACHY it is important to exclude the possibility that the retrieved elevated tropical $\mathrm{XCH}_{4}$ is an artifact of the $\mathrm{CO}_{2}$ normalization used to compute the $\mathrm{XCH}_{4}$. To investigate 

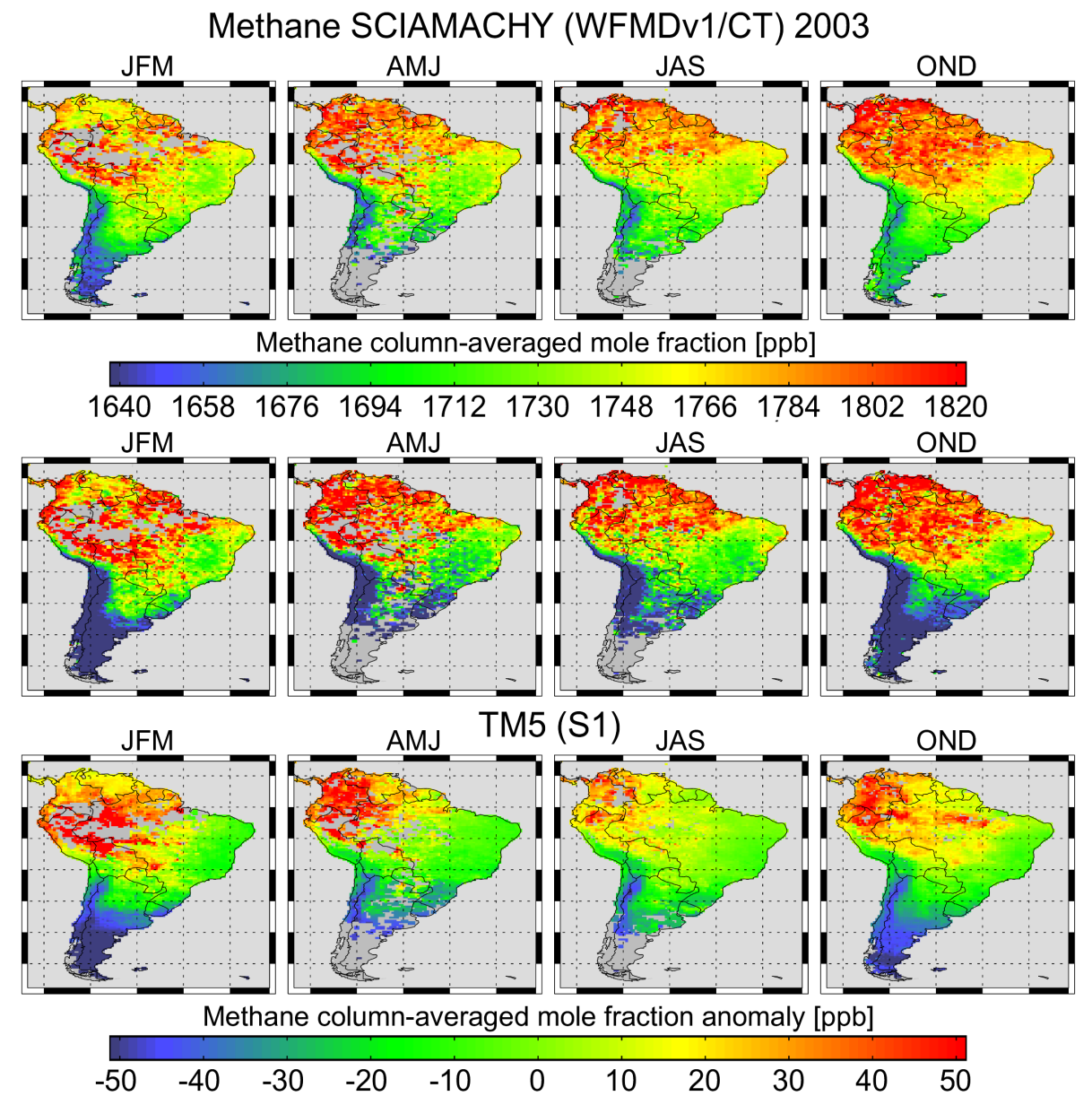

Fig. 7. As Fig. 5 but for South America.

this, we compared our standard $\mathrm{XCH}_{4}$ data product, which is influenced by $\mathrm{CO}_{2}$, by alternative $\mathrm{XCH}_{4}$ data products not influenced by $\mathrm{CO}_{2}$. The alternative $\mathrm{XCH}_{4}$ data products are obtained by dividing the retrieved methane columns by dry air columns obtained from (i) simultaneously retrieved $\mathrm{O}_{2}$ columns (as used for our $\mathrm{XCO}_{2}$ data product described in Schneising et al., 2008a) and (ii) using dry air columns obtained from meteorological surface pressure. The analysis has shown that the elevated methane over the tropics is also visible when using measured $\mathrm{O}_{2}$ instead of measured $\mathrm{CO}_{2}$. According to Fig. 12 of Schneising et al. (2008b) using $\mathrm{O}_{2}$ instead of $\mathrm{CO}_{2}$ results in even higher tropical $\mathrm{XCH}_{4}$, but this is probably due to the larger measurement error expected for using $\mathrm{O}_{2}$ instead of $\mathrm{CO}_{2}$, in particular in the presence of subvisual (very thin) cirrus clouds (Schneising et al., 2008a). We found that the retrieved methane is also larger over the tropics compared to TM5 when the analysis is restricted to, for example, August-November 2003, i.e., for the time period discussed in Frankenberg et al. (2005b), regardless of whether $\mathrm{CO}_{2}$ or $\mathrm{O}_{2}$ is used for normalization of the methane columns. We also found that tropical methane is enhanced when methane is normalized by meteorological surface pressure instead of measured $\mathrm{CO}_{2}$ or $\mathrm{O}_{2}$. The fact that the retrieved methane enhancement is stable under the change of normalization method gives evidence that methane is actually higher over tropical rain forests than expected by the TM5 model pointing to an unconsidered or significantly underestimated known methane source (firstly suggested by Frankenberg et al., 2005b). At least it can be excluded that the enhancement is introduced artificially by the $\mathrm{CO}_{2}$ normalization. In this context it is also important to point out that the high tropical methane (compared to TM5) has also been observed using an entirely different methane spectral fitting window. This has been shown in Buchwitz et al. (2005b) using WFM-DOAS version 0.41 applied to methane absorption lines located in SCIAMACHY channel 8 (2265-2280 nm). Our results reveal that the elevated tropical methane compared to the model is nearly independent of the $\mathrm{CO}_{2}$ (CarbonTracker) correction as shown in, e.g., Figs. 4 and 8. In summary, we conclude from this analysis that the elevated tropical methane observed by SCIAMACHY appears to be a robust feature. For the Amazon basin it has 

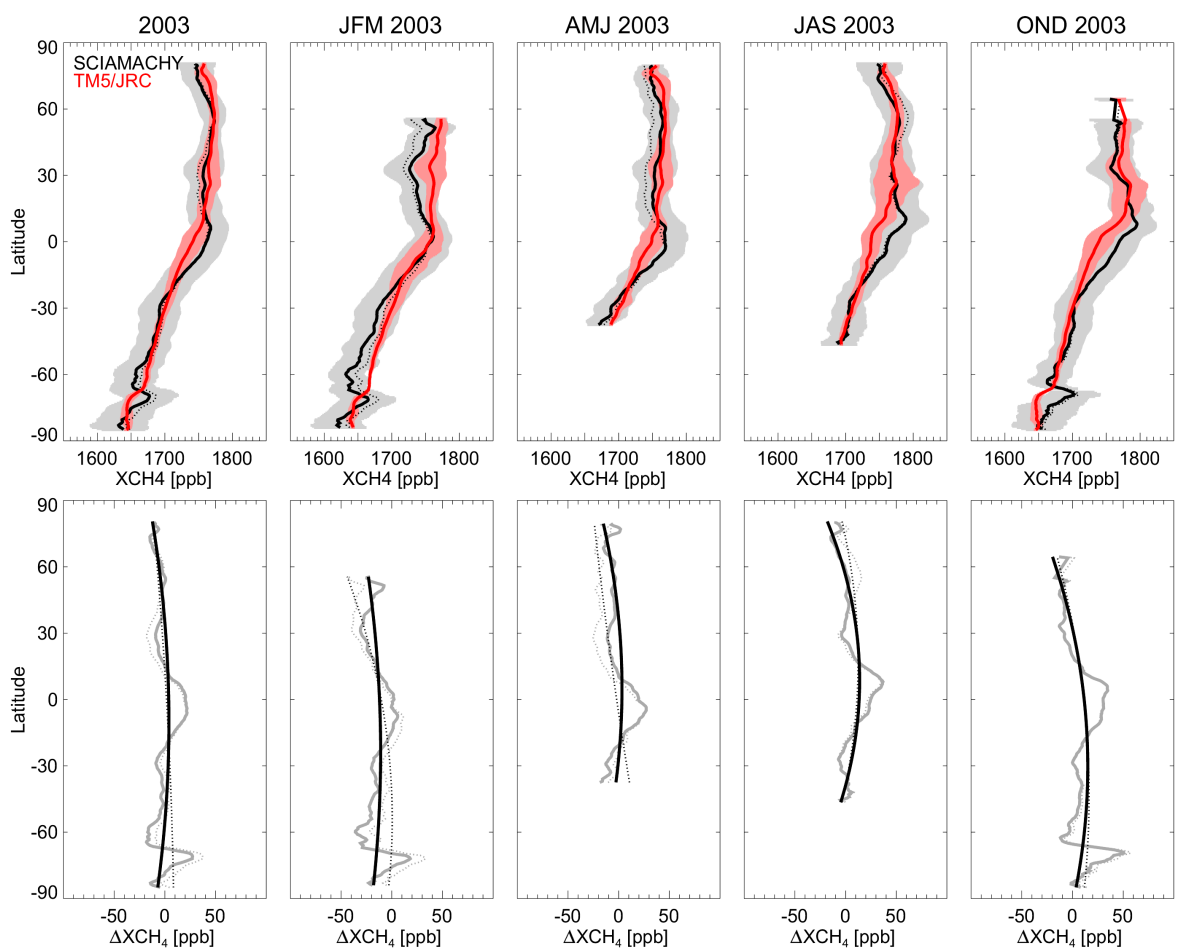

Fig. 8. Comparison of latitudinal averages of SCIAMACHY WFM-DOAS methane retrievals (black) and TM5 simulations (red) for the entire year 2003 (left) and for the four seasons as also used for Fig. 4. For the comparison both the SCIAMACHY and TM5 data have been gridded on a common $0.5^{\circ} \times 0.5^{\circ}$ latitude/longitude grid. The shaded areas illustrate the standard deviations. The bottom panels show the difference SCIA-TM5 and a quadratic polynomial fitted to it. For SCIAMACHY the solid lines correspond to considering CarbonTracker $\mathrm{CO}_{2}$ for the computation of $\mathrm{XCH}_{4}$, whereas the dotted lines correspond to assuming a constant $\mathrm{CO}_{2}$ mole fraction. As can be seen, the consideration of the seasonal $\mathrm{CO}_{2}$ variability from CarbonTracker in the SCIAMACHY XCH 4 product leads to a better agreement with the TM5 model simulation concerning seasonal variability and seasonal latitudinal bias. Note that the SCIAMACHY $\mathrm{XCH}_{4}$ has been scaled with $1.01\left(\mathrm{CO}_{2}\right.$ from CarbonTracker) and $1.02\left(\mathrm{CO}_{2}\right.$ constant), respectively, to compensate for a systematic low bias relative to the TM5 model.

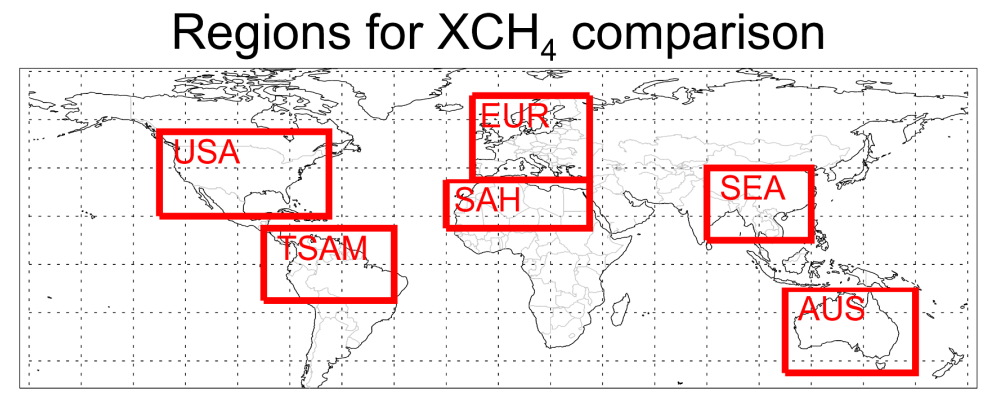

Fig. 9. Six regions selected for a comparison of the SCIAMACHY and TM5 methane column averaged mole fractions shown in Fig. 10: North America (USA), Europe (EUR), Tropical South America (TSAM), Sahara (SAH), South-East Asia (SEA), and Australia (AUS).

also been recently confirmed using airborne measurements that methane emissions in this region appear to be higher that hitherto known (Miller et al., 2007). Although our study is consistent with the findings of Frankenberg et al. (2005b) it is important to point out that the tropical $\mathrm{XCH}_{4}$ enhancement is only about $2 \%$, i.e., a fairly small signal. Therefore one has to be careful with a quantitative interpretation especially be- cause the absolute magnitude of the enhancement decreases to a certain extent when using updated water vapour line parameters accounting for spectroscopic interferences with methane in the considered spectral range (Frankenberg et al. (2008b), see also Section 6).

The latitudinal averages and global annual composite averages of three years of SCIAMACHY $\mathrm{XCH}_{4}$ retrievals, when 

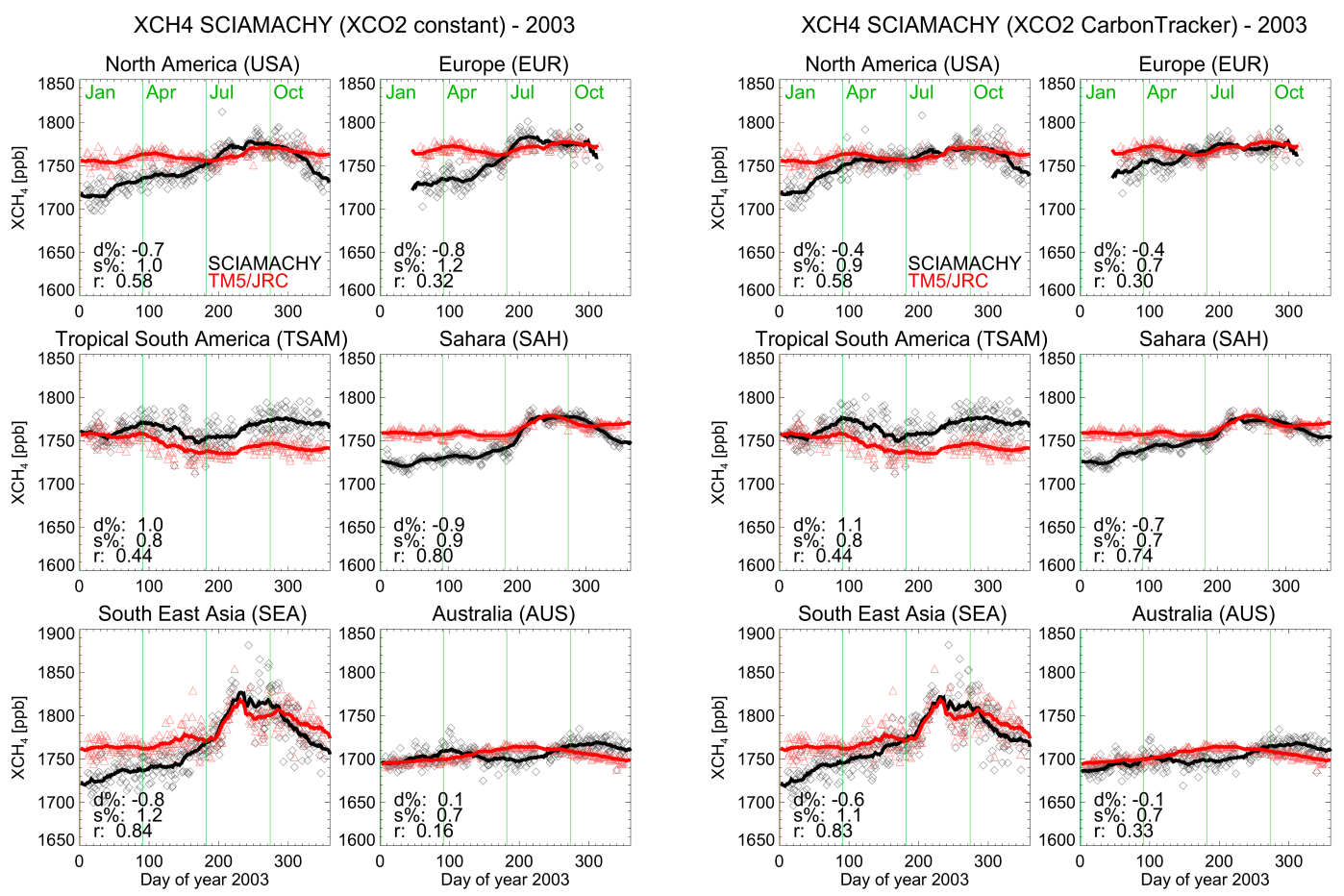

Fig. 10. Comparison of the SCIAMACHY methane (black) with TM5 model simulations (red). The six left panels show the comparison for the six regions displayed in Fig. 9 for the standard SCIAMACHY $\mathrm{XCH}_{4}$ computed using a constant $\mathrm{CO}_{2}$. For the comparison both the daily SCIAMACHY and TM5 data have been gridded on a common $0.5^{\circ} \times 0.5^{\circ}$ latitude/longitude grid. The symbols show the daily averages of all coincident grid cells in a given region. For SCIAMACHY all measurement have been averaged for which the WFMDv1.0 quality flag indicates a good measurement. The solid lines represent a 30 days running average. For each region the following numbers have been computed based on the (not smoothed) daily averages: $d \%$ is the mean difference SCIA-TM5 in percent, $s \%$ denotes the standard deviation of the difference in percent, and $r$ is the correlation coefficient. To assess the impact of assuming a constant carbon dioxide mole fraction the six right panels show the same comparison but using CarbonTracker $\mathrm{CO}_{2}$ for the computation of the measured $\mathrm{XCH}_{4}$. As can be seen from a comparison of the left and the right panels, the differences are relatively small, although not zero. The CarbonTracker correction leads generally to better agreement with the TM5 model, especially over the Northern Hemisphere where the $\mathrm{CO}_{2}$ seasonal cycle is more pronounced. Note that the SCIAMACHY $\mathrm{XCH}_{4}$ has been scaled with 1.02 (left six panels) and 1.01 (right six panels) to compensate for a systematic low bias relative to the TM5 model.

accounting for $\mathrm{CO}_{2}$ variability by modeled carbon dioxide from CarbonTracker, are shown in Fig. 11. As can be seen, the spatial pattern and the latitudinal dependence of the retrieved $\mathrm{XCH}_{4}$ is quite similar for 2003 and 2004. For 2005 the $\mathrm{XCH}_{4}$ is higher over the Northern Hemisphere and also appears to be more variable. Over the Northern Hemisphere the methane is about $1 \%$ higher in 2005 compared to 2003 and 2004 in contrast to the surface observations (see e.g. http://www.esrl.noaa.gov/gmd/aggi/). The regional analysis of the inter-annual variability for the three years displayed in Fig. 12 shows similar seasonal cycles but also larger scatter of the SCIAMACHY $\mathrm{XCH}_{4}$ in the year 2005. Figure 13 suggests that this scatter is due to the retrieved methane columns and not due to carbon dioxide as the root-mean-square (RMS) of the spectral fit residua (a measure of the instrument noise) is larger for methane for 2005 compared to the two previous years whereas for $\mathrm{CO}_{2}$ the RMS is rather stable. Figure 14 shows that the standard deviations of the spectral fit residua is larger for 2005 compared to the two previous years especially in the wavelength range where the methane absorption is largest ( $\mathrm{Q}$ branch at $1666 \mathrm{~nm}$ ). Hence, the significant higher variability of the retrieved $\mathrm{XCH}_{4}$ is most likely due to somewhat larger noise of the spectral measurements in 2005 compared to the two previous years. It is known that the SCIAMACHY near-infrared detectors are on average degrading with time (this holds especially for channels 7 and 8 not used for this study and for channel 6+ used for this study for methane column retrieval; channel 6 , used for $\mathrm{CO}_{2}$ column retrieval, is in contrast very stable). A detailed discussion of this is given in Kleipool et al. (2007) where it is also shown that the behaviour of the individual detector pixels is quite complicated including the possibility that degrading pixels recover. For the future we plan to process a longer time series to investigate how the performance of the channels behave after 2005 . 

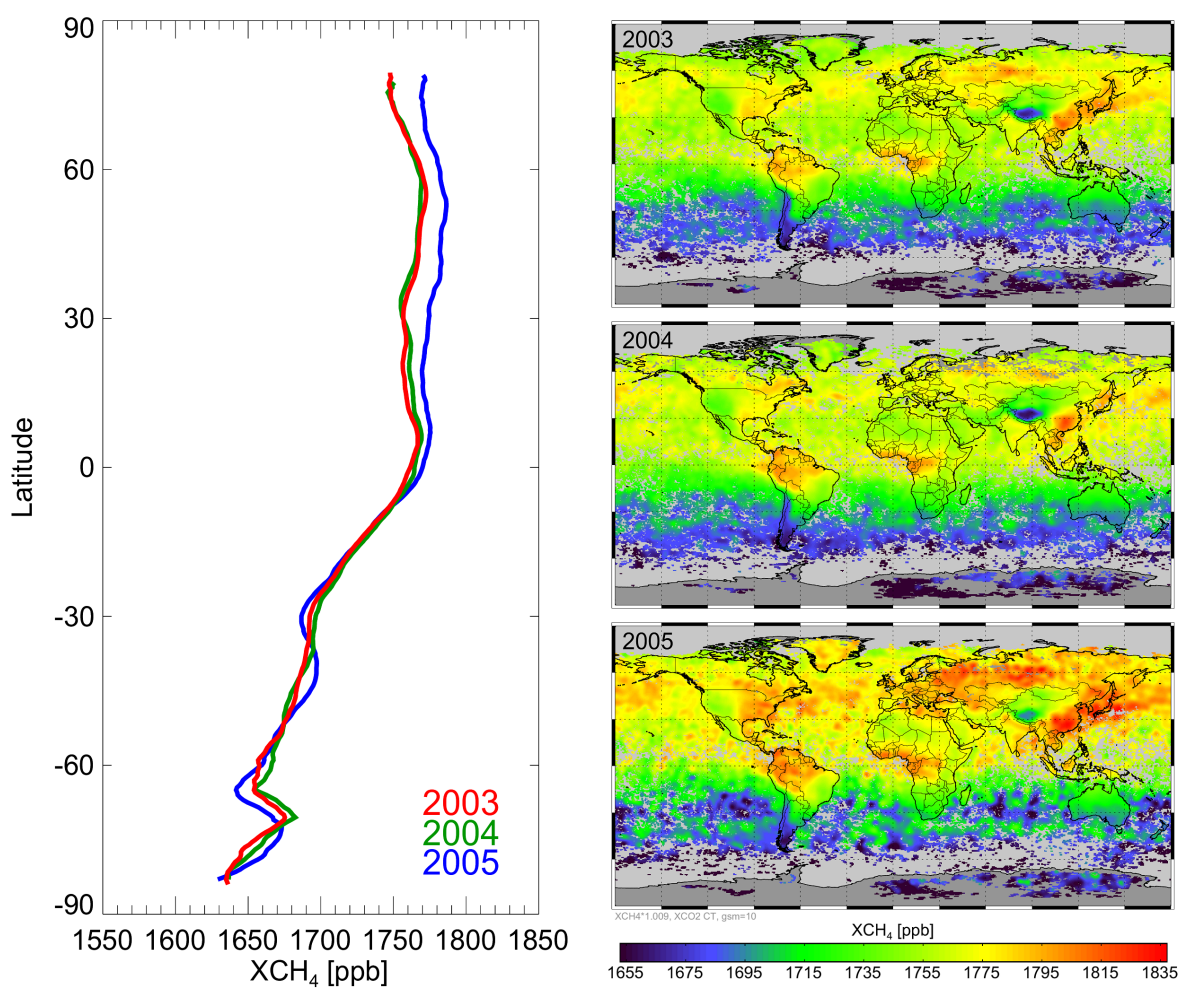

Fig. 11. Latitudinal averages (left) and global annual composite average maps (right) of three years of $\mathrm{SCIAMACHY} \mathrm{XCH}_{4}$ retrieved by WFM-DOAS version 1.0 using CarbonTracker to account for $\mathrm{CO}_{2}$ variability.

For the year 2004 the WFM-DOAS v1.0 SCIAMACHY $\mathrm{XCH}_{4}$ data set presented here has been inverted for methane surface fluxes using a newly developed 4D-VAR inverse modelling scheme (Meirink et al., 2008a,b) referred to as TM5-4DVAR in the following.

A detailed discussion of the retrieved methane fluxes is out of the scope of this manuscript but the main findings can be shortly summarized as follows:

(i) The methane fluxes obtained by applying TM5-4DVAR to background surface stations only are consistent (nearly identical) with the methane fluxes obtained from this data set using the alternative synthesis inversion method presented in Bergamaschi et al. (2007). This verifies the implementation of the new TM5-4DVAR inverse modelling scheme.

(ii) The methane fluxes obtained by applying TM5-4DVAR to the WFM-DOAS v1.0 methane data set presented here are consistent with the methane fluxes obtained by applying TM5-4DVAR to the IMAP-DOAS v1.1 methane data set (Meirink et al., 2008b). From this one can conclude that for 2003 the two SCIAMACHY methane data sets which have been generated using two independently developed retrieval algorithms (WFMDOAS v1.0 and IMAP-DOAS v1.1) give similar results in terms of retrieved larger scale regional methane surface fluxes.

However, a source inversion using an updated IMAPDOAS version, based on spectroscopic parameters by Frankenberg et al. (2008a) and manually modified water vapour parameters of Jenouvrier et al. (2007), leads to a considerable decrease of the estimated elevated tropical emissions being more consistent with inversions based on NOAA surface measurements only (Frankenberg et al., 2008b). The impact of spectroscopy on WFM-DOAS methane is expected to be similar and is discussed in the following section.

\section{Sensitivity to spectroscopy}

To analyse the sensitivity of the WFM-DOAS methane retrievals to spectroscopy, particularly with regard to the absolute magnitude of the retrieved tropical enhancement linked to possible inaccuracies in the HITRAN spectroscopic data and an associated potential methane overestimation in cases of high water vapour abundances due to unaccounted spectroscopic interferences (Frankenberg et al., 2008b), the entire $\mathrm{CH}_{4}$ data set was reprocessed (referred to as WFM-DOAS v1.1 in the following) using updated methane (Frankenberg et al., 2008a) and water vapour line parameters (Jenouvrier et al., 2007) in the associated near-infrared fitting window 

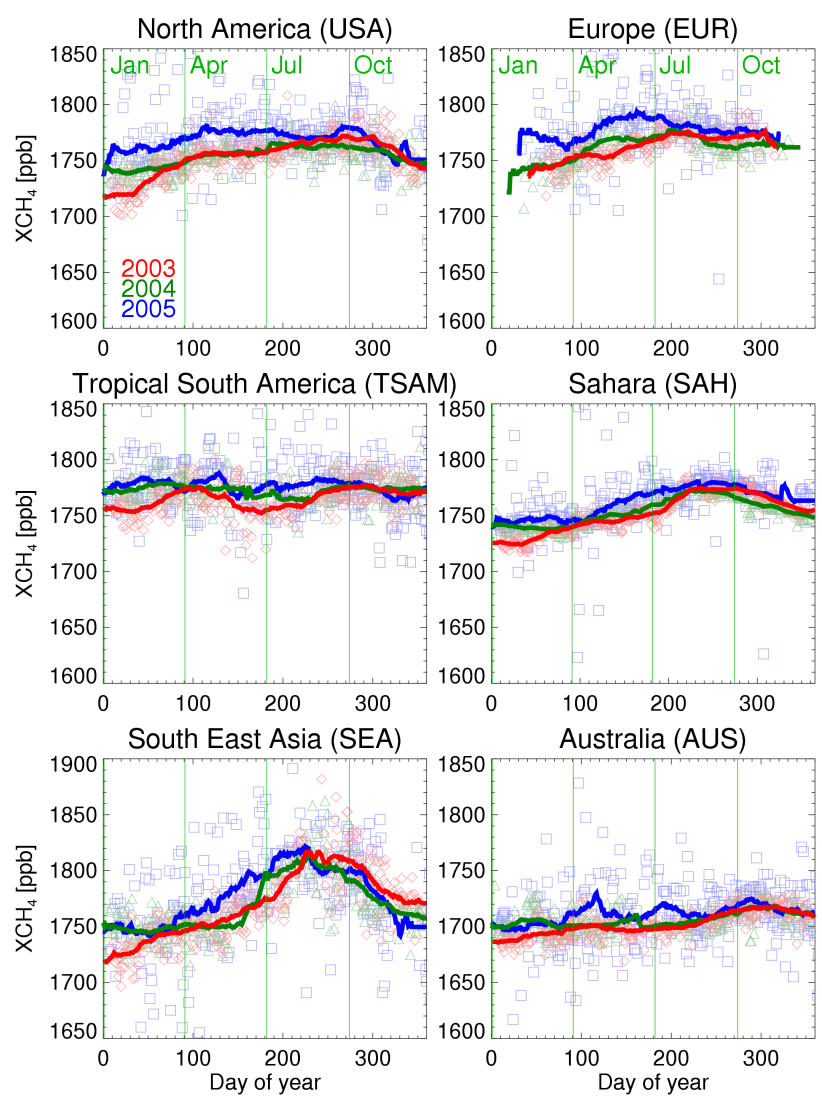

Fig. 12. Time series of SCIAMACHY methane for the years 2003 (red), 2004 (green), and 2005 (blue) for the six regions shown in Fig. 9. The symbols denote daily averages, the solid lines represent a 30 days running average.

without changing anything else. In contrast to Frankenberg et al. (2008b) the Jenouvrier water vapour spectroscopic parameters were taken as is without manually adjusting broadening coefficients, pressure shifts or line strengths. For missing shift or broadening parameters, standard values were assumed universally.

Consistent with the results reported in Frankenberg et al. (2008b) we also find a positive correlation of the SCIAMACHY and TM5 methane ratio with water vapour which is reduced when the updated spectroscopy is used. This is illustrated in Fig. 15. The water vapour data set used for the comparison is retrieved from the SCIAMACHY spectral measurements in the visible wavelength region (Noël et al., 2004). The considered time period from January through July 2003 was chosen to avoid methane transport from the strong Asian source regions at the end of the year. As can be seen, the correlation vanishes almost entirely over Australia but is only reduced over Sahara. This shows that the effect depends on the region. The effect is qualitatively consistent with the findings of Frankenberg et al. (2008b) (their Fig. 2). Quantitatively, however, there are differences. For IMAP-DOAS, for example, the correlation vanishes over Sa-
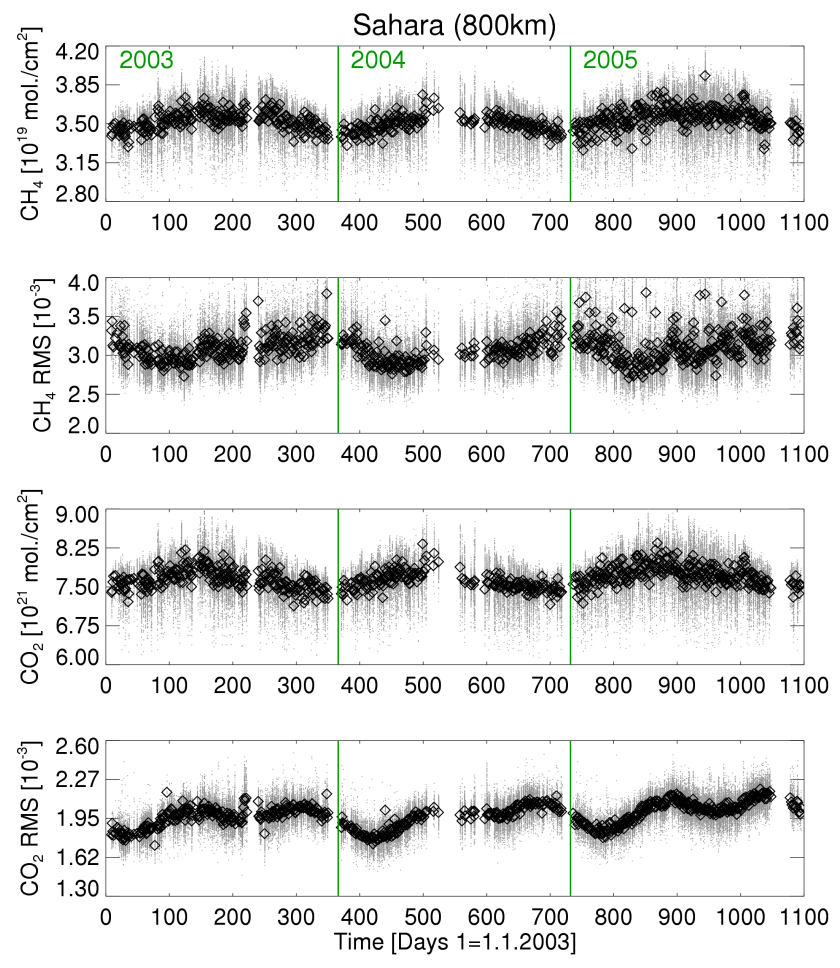

Fig. 13. Time series of methane columns (top panel) and carbon dioxide columns (third panel) and the corresponding root-meansquare (RMS) of the fit residua (= relative difference between measurement and radiative transfer model after the fit) in the Sahara in a radius of $800 \mathrm{~km}$ around $25^{\circ} \mathrm{N}, 10^{\circ} \mathrm{E}$. The second panel shows the RMS of the methane fit, the bottom panel shows the RMS of the $\mathrm{CO}_{2}$ fit. All single measurements passing the quality filter are shown as grey dots while the black square symbols denote daily averages.

hara. We also investigated if the quality of the spectral WFMDOAS fits depend on the amount of water vapour. The results are shown in Fig. 16. As can be seen, using the updated spectroscopy results in a (dubious) positive correlation of the RMS of the $\mathrm{CH}_{4}$ fit residuum with specific humidity which is not existent for the HITRAN spectroscopy. Additionally, the systematic low bias of the SCIAMACHY data relative to the model is further increased after the update of spectroscopy.

Figure 17 shows a comparison of WFM-DOAS v1.0 and v1.1 yearly averages for the year 2003 of measurements passing the quality filter simultaneously for both spectroscopies appropriately scaled to be on average on the same level as the model (scaling factors 1.01 for v1.0 and 1.03 for v1.1), as well as the difference of the two retrieval versions which only differ in methane and water vapour spectroscopic parameters. As can be seen, the main difference between the two data sets is the decrease by up to about 20 ppb or $1 \%$ of the absolute magnitude of the tropical enhancement in better agreement with the model when using the updated spectroscopy. This is less than the about $60 \mathrm{ppb}$ reduction reported in 


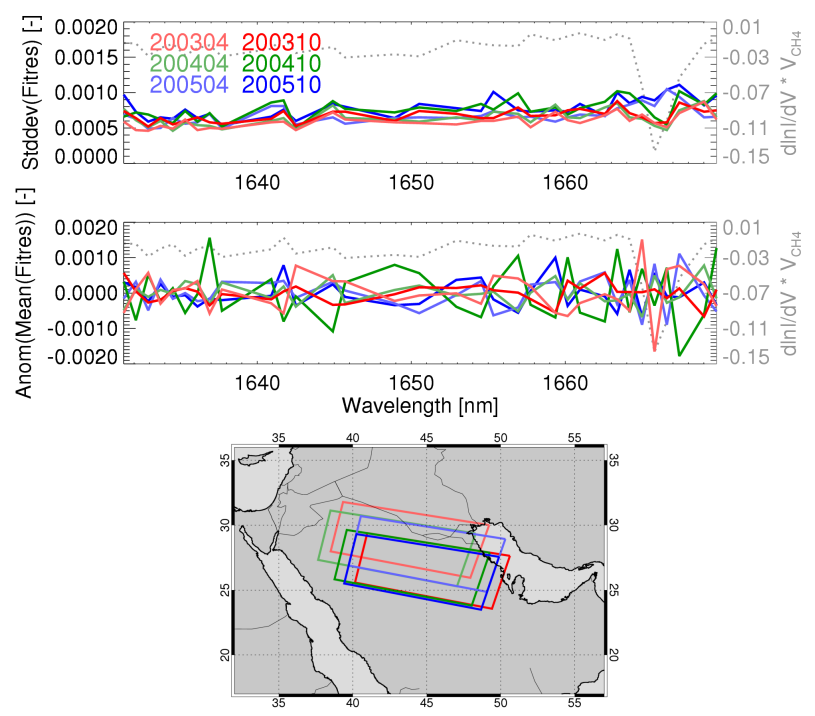

Fig. 14. Analysis of the cause of the larger scatter of the retrieved methane columns in 2005. The top panel shows the temporal evolution of the standard deviations of the fit residua of all retrievals passing the quality filter for six selected nadir states covering a specific Arabian region (a nadir state corresponds to about one minute nadir observations; the spatial regions covered by these states are shown in the bottom panel). The dotted grey lines shows the spectral positions of the methane absorption features (i.e., the methane weighting function (radiance derivative) scaled by the retrieved methane column; right axis). The top panel shows that the standard deviation, especially at two detector pixels (pixel number 894 and 895 of channel 6) which are located where the strongest methane absorption occurs, is considerably higher in 2005 (blue) compared to 2003 (red) and 2004 (green) indicating a possible degradation of these detector pixels especially in terms of larger noise. The middle panel shows the averages of the fit residua (shown as anomalies, i.e., with mean value subtracted) for the same six nadir states. As there are no obvious systematic differences for the different years it appears that the degradation is mainly random rather than systematic.

Frankenberg et al. (2008b). We cannot offer a clear explanation for this difference but one has to consider that the two retrieval algorithms WFM-DOAS and IMAP-DOAS are quite different, that different time periods have been investigated, and that also different filtering schemes are used to identify the successful retrievals (sufficiently cloud free, etc.). One of the differences is that Frankenberg et al. (2008b) are using modified water line parameters whereas we use the original line parameters of Jenouvrier et al. (2007). However, based on simulated retrievals we conclude that this can only explain about $0.3 \%$ of the differences which is consistent with the findings reported in Frankenberg et al. (2008b).

The updated spectroscopy results in less data especially over the tropics. This is in line with the findings linked to Fig. 16 as the fits are getting systematically worse in cases of high water vapour abundances when using the updated spectroscopy. Thus, the occasional very high humidity over the tropics apparently leads to lower quality fits associated to the new line parameters not passing the filter criteria anymore.

Concerning inter-annual variability our analysis showed that the retrieved methane elevation in 2005 relative to 2003/2004 ascribed to somewhat larger noise of the spectral measurements, which is inconsistent with surface observations, is even increasing when using the updated spectroscopy reinforcing the impression of less stability of the spectral fits. Nevertheless, the better agreement of WFMD v1.1 with the model concerning tropical methane sources is generally also valid as regards latitudinal biases or regional time series. For example the seasonal variations over Australia agree perceptibly better with TM5 than for the HITRAN line parameters in line with the findings of Frankenberg et al. (2008a).

In summary, our first analysis did not unambiguously establish advantages in using the updated spectroscopy according to line parameters by Frankenberg et al. (2008a) and Jenouvrier et al. (2007) indicating that the HITRAN and the new spectroscopy are both potentially suffering from inaccuracies adversely affecting the retrieval results albeit in a different way. It has become clear that the accurate knowledge of spectroscopic parameters is very important with respect to precise quantification of regional enhancements over source regions and corresponding fluxes obtained via inverse modelling as small changes in spectroscopy can have a significant impact on the retrievals in cases of spectroscopic interferences of different absorbers because the SCIAMACHY resolution does not resolve individual absorption lines. This has to be borne in mind in future retrievals and is in principle crucial for all gases with demanding accuracy requirements especially for the long-lived and therefore well mixed greenhouse gases.

\section{Conclusions}

For the first time we have presented and discussed a global three-year data set covering the time period 2003-2005 of atmospheric methane column-averaged dry air mole fractions, $\mathrm{XCH}_{4}$, retrieved from the spectral near-infrared nadir observations of the SCIAMACHY instrument onboard the European environmental satellite ENVISAT benefiting from the simultaneous retrieval of $\mathrm{CH}_{4}, \mathrm{CO}_{2}$, and $\mathrm{O}_{2}$ vertical columns. The data set has been retrieved using the improved version 1.0 of the retrieval algorithm WFM-DOAS.

We have presented detailed comparisons with global model simulations using the TM5 model, which has been optimized versus highly accurate but sparse surface measurements from the NOAA/ESRL network (scenario S1 from Bergamaschi et al., 2007). The comparison results are consistent with the findings of Dils et al. (2006b) who performed a comparison of the SCIAMACHY $\mathrm{XCH}_{4}$ with FTIR $\mathrm{XCH}_{4}$ measurements at seven European ground stations. As the SCIAMACHY $\mathrm{XCH}_{4}$ is obtained using simultaneously 

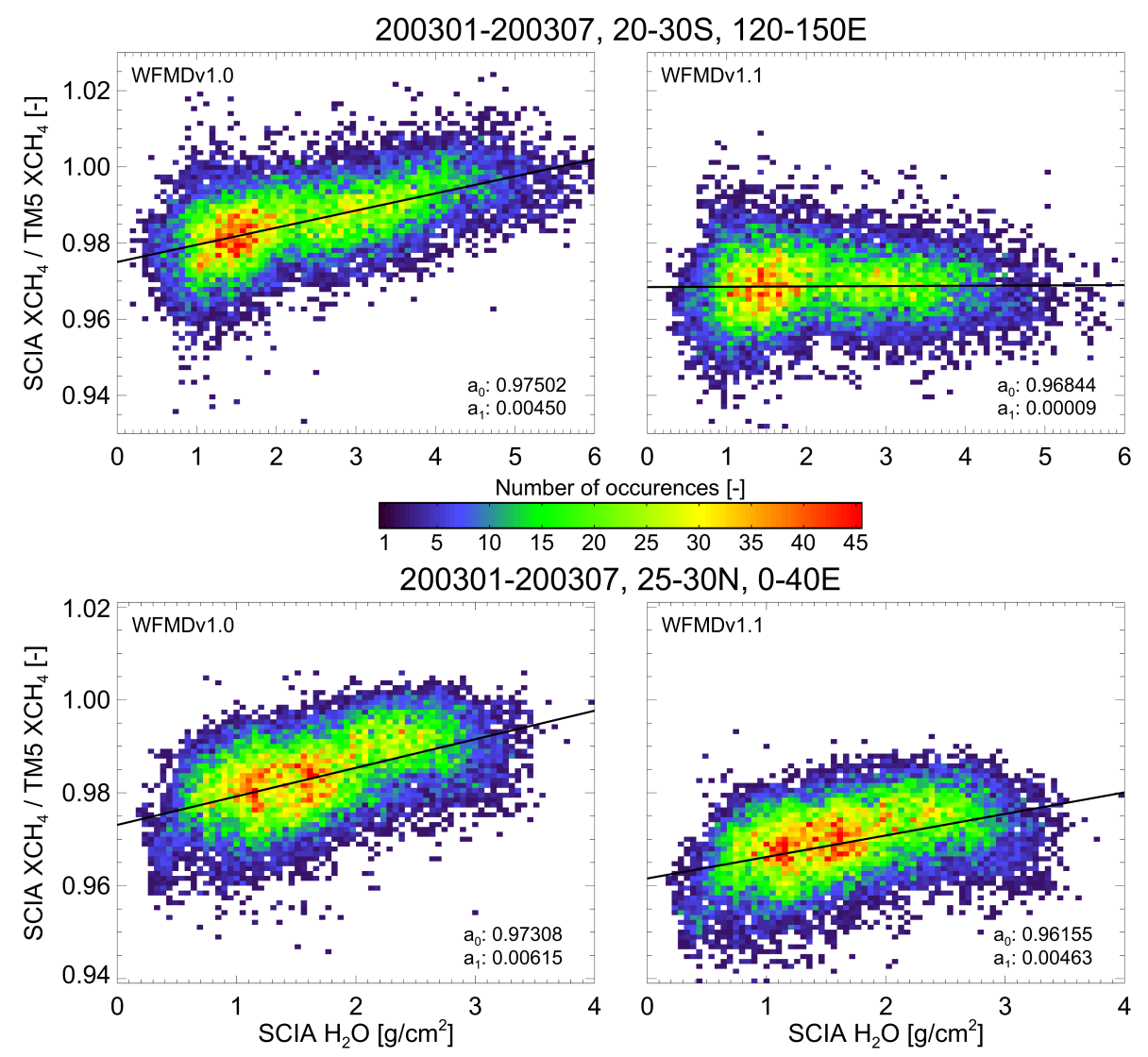

Fig. 15. Frequency distribution of the methane ratio SCIAMACHY/TM5 as function of the water vapour amount for the HITRAN spectroscopy (left) compared to the updated spectroscopy of Frankenberg et al. (2008a) and Jenouvrier et al. (2007) over Australia (top) and the Sahara (bottom). Also given are the linear fit parameters $a_{0}$ and $a_{1}$.

retrieved $\mathrm{CO}_{2}$ columns as a proxy for the light path we investigated to what extent the SCIAMACHY $\mathrm{XCH}_{4}$ data product is influenced by $\mathrm{CO}_{2}$ variability. For this purpose we used $\mathrm{CO}_{2}$ fields from NOAA's $\mathrm{CO}_{2}$ assimilation system CarbonTracker. We found that the regional patterns of methane are only marginally affected by $\mathrm{CO}_{2}$ but that using CarbonTracker helps to reduce seasonal and latitudinal $\mathrm{XCH}_{4}$ biases caused by $\mathrm{CO}_{2}$ variability. Therefore, for most of the results presented in this paper, the SCIAMACHY $\mathrm{XCH}_{4}$ has been corrected for $\mathrm{CO}_{2}$ variability (using CarbonTracker).

From the comparison with TM5 and an error analysis of the retrieval algorithm we conclude that the SCIAMACHY $\mathrm{XCH}_{4}$ data set can be characterized by (i) a single ground pixel retrieval precision of about $1.7 \%$ as concluded, for example, from the mean of the standard deviations of the daily data at a given location being consistent with the standard deviation of the retrieved $\mathrm{XCH}_{4}$ relative to the model and European FTS measurements and (ii) a systematic low bias of about $1 \%$ as concluded from the mean difference relative to TM5 (after $\mathrm{CO}_{2}$ correction). The underestimation of the SCIAMACHY $\mathrm{XCH}_{4}$ of about $2 \%$ when assuming a constant $\mathrm{CO}_{2}$ mole fraction of $370 \mathrm{ppm}$ (i.e., without $\mathrm{CO}_{2}$ correction) is consistent with the findings of Dils et al. (2006b) as discussed above. After scaling the methane mole fractions appropriately to account for the low bias, agreement with the model is typically within about $1-2 \%$.

In agreement with previous studies (Frankenberg et al., 2005b, 2006; Buchwitz et al., 2006a) we found higher methane over the tropics compared to the model. Concerning the ongoing discussion of the discovery of a new methane source or a significantly underestimated known source (e.g. wetland emissions) in the tropics (Keppler et al., 2006; Crutzen et al., 2006; Houweling et al., 2006; Bergamaschi et al., 2007; Miller et al., 2007; Dueck et al., 2007), we found that it appears unlikely that the elevated tropical methane measured by SCIAMACHY is caused artificially in the retrieval by lower than assumed tropical $\mathrm{CO}_{2}$ (note that the SCIAMACHY column-averaged mole fraction of methane is obtained by normalizing with simultaneously measured $\mathrm{CO}_{2}$ to reduce systematic light path related errors). Our conclusion is based on the finding that we also observe enhanced tropical methane when we use a SCIAMACHY $\mathrm{XCH}_{4}$ data product not influenced by $\mathrm{CO}_{2}$. However, the magnitude of the retrieved tropical methane enhancement is sensitive to 

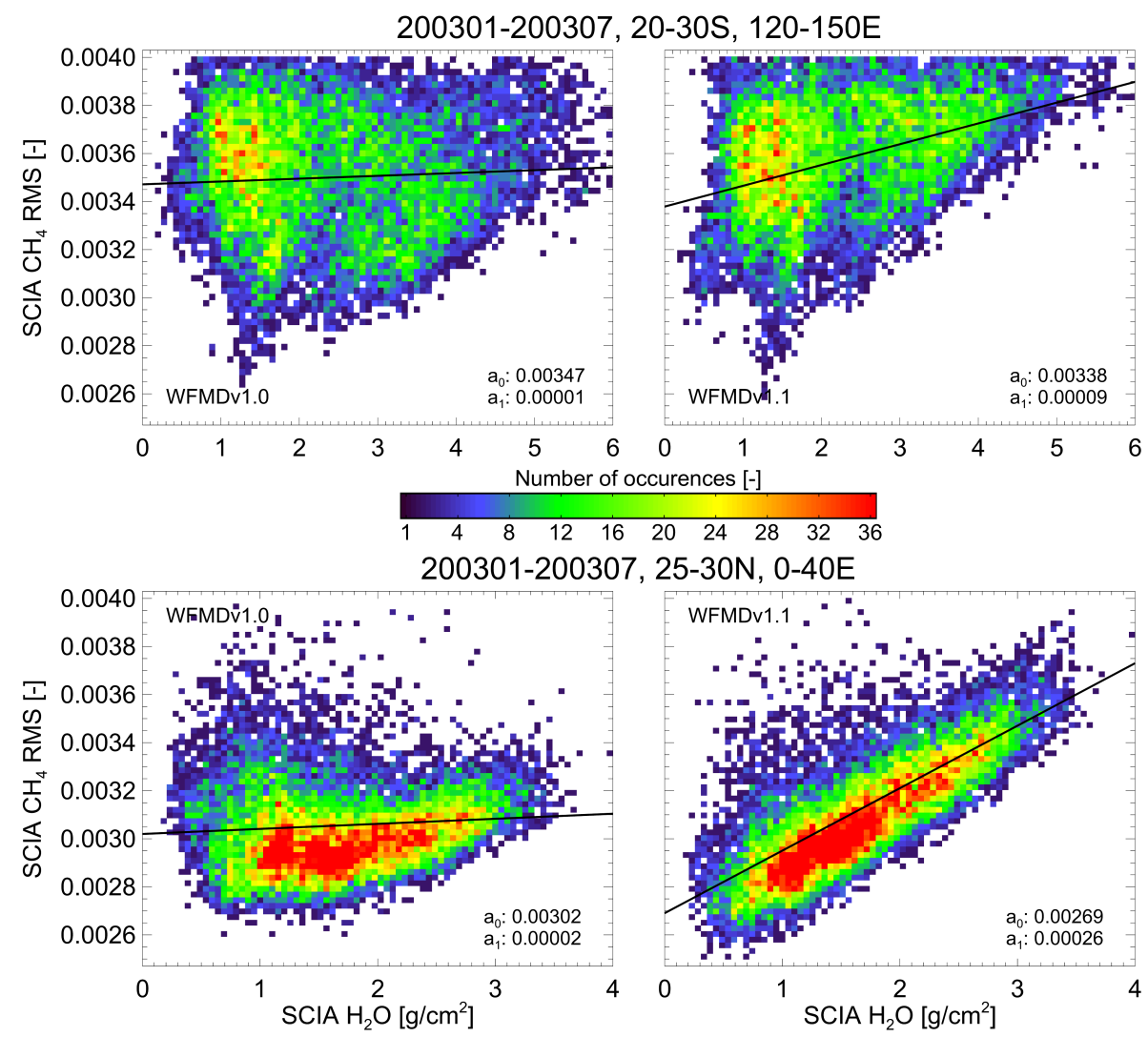

Fig. 16. As Figure 15 but for the $\mathrm{RMS}$ of the $\mathrm{CH}_{4}$ fit residuum as function of the water vapour column. Using the new spectroscopy leads to a positive correlation of the $\mathrm{RMS}$ of the $\mathrm{CH}_{4}$ fit residuum with specific humidity.
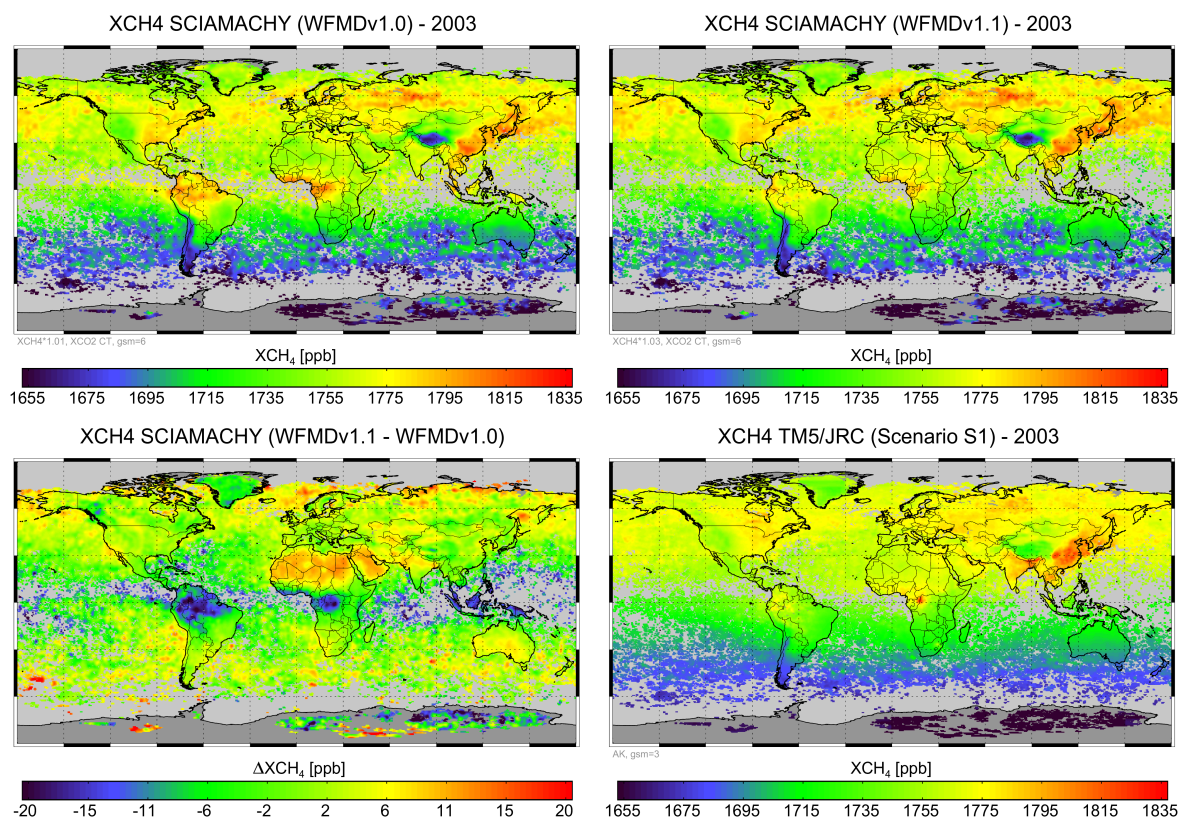

Fig. 17. Comparison of the two methane data sets using HITRAN (top left) and updated spectroscopy (top right). The difference is shown in the bottom left and the corresponding TM5 model simulation in the bottom right panel. 
the choice of spectroscopic parameters and might be overestimated as the usage of an updated spectroscopy by Jenouvrier et al. (2007) and Frankenberg et al. (2008a) accounting for spectroscopic interferences with water vapour results in about $1 \%$ lower tropical methane mole fractions unfortunately connected with less stable fit results in the presence of high humidity. Our results are broadly consistent with the finding of Frankenberg et al. (2008b).

Concerning inter-annual variability we find similar methane spatio-temporal patterns for 2003 and 2004. For 2005 the retrieved methane shows significantly $(\sim 2 \%)$ higher variability compared to the two previous years, most likely due to larger noise of the spectral measurements.

The SCIAMACHY WFM-DOAS v1.0 $\mathrm{XCH}_{4}$ data set discussed here is available from the authors on request. Details concerning data access as well as supplementary information such as monthly composite maps covering the entire three years time period are given on the SCIAMACHY/WFMDOAS website http://www.iup.uni-bremen.de/sciamachy/ NIR_NADIR_WFM_DOAS/index.html.

In the future we will aim at further improving the retrieval algorithm taking into account, for example, updates of the spectroscopic line parameters and pressure, temperature and water vapor vertical profiles from meteorological analysis.

Acknowledgements. We thank ESA and DLR for providing us with the SCIAMACHY Level 1 data and the SCIAMACHY calibration team (DLR, SRON, University of Bremen, ESA, and others) for continuously improving the quality of the spectra. We thank the NASA/GSFC TOMS Ozone Processing Team (OPT) for providing TOMS/EP AAI data (obtained from http://toms.gsfc.nasa.gov/) and NOAA/ESRL/GMD (P. Tans and collegues) for the CarbonTracker $\mathrm{CO}_{2}$ fields. Funding for this study came from DLR-Bonn (grant 50EE0727), ESA (GMES Service Element (GSE) project PROMOTE led by DLR-Oberpfaffenhofen), the European Commission (FP6 AMFIC, FP7 CITYZEN), and from the University and the State of Bremen. We acknowledge exchange of information within the European Commission FP6 Network of Excellence ACCENT.

Edited by: P. Monks

\section{References}

Bergamaschi, P., Frankenberg, C., Meirink, J. F., Krol, M., Dentener, F., Wagner, T., Platt, U., Kaplan, J. O., Körner, S., Heimann, M., Dlugokencky, E. J., and Goede, A.: Satellite chartography of atmospheric methane from SCIAMACHY onboard ENVISAT: 2. Evaluation based on inverse model simulations, J. Geophys. Res., 112, D02304, doi:10.1029/2006JD007268, 2007.

Bergamaschi, P., Krol, M., Dentener, F., Vermeulen, A., Meinhardt, F., Graul, R., Ramonet, M., Peters, W., and Dlugokencky, E. J.: Inverse modelling of national and European $\mathrm{CH} 4$ emissions using the atmospheric zoom model TM5, Atmos. Chem. Phys., 5, 2431-2460, 2005,

http://www.atmos-chem-phys.net/5/2431/2005/.

Berk, A., Bernstein, L. S., Anderson, G. P., Acharya, P. K., Robertson, D. C., Chetwynd, J. H., and Adler-Golden, S. M.: MOD-
TRAN cloud and multiple scattering upgrades with application to AVIRIS, Remote Sens. Environ., 65, 3, 367-375, 1998.

Bousquet, P., Ciais, P., Miller, J. B., Dlugokencky, E. J., Hauglustaine, D. A., Prigent, C., Van der Werf, G. R., Peylin, P., Brunke, E.-G., Carouge, C., Langenfelds, R. L., Lathiere, J., Papa, F., Ramonet, M., Schmidt, M., Steele, L. P., Tyler, S. C., and White, J.: Contribution of anthropogenic and natural sources to atmospheric methane variability, Nature, 443, 439443, doi:10.1038/nature05132, 2006.

Bovensmann, H., Burrows, J. P., Buchwitz, M., Frerick, J., Noël, S., Rozanov, V. V., Chance, K. V., and Goede, A.: SCIAMACHY Mission Objectives and Measurement Modes, J. Atmos. Sci., 56, 127-150, 1999.

Buchwitz, M., Schneising, O., Burrows, J. P., Bovensmann, H., Reuter, M., and Notholt, J.: First direct observation of the atmospheric $\mathrm{CO}_{2}$ year-to-year increase from space, Atmos. Chem. Phys., 7, 4249-4256, 2007, http://www.atmos-chem-phys.net/7/4249/2007/.

Buchwitz, M., de Beek, R., Noël, S., Burrows, J. P., Bovensmann, H., Schneising, O., Khlystova, I., Bruns, M., Bremer, H., Bergamaschi, P., Körner, S., and Heimann, M.: Atmospheric carbon gases retrieved from SCIAMACHY by WFM-DOAS: version $0.5 \mathrm{CO}$ and $\mathrm{CH}_{4}$ and impact of calibration improvements on $\mathrm{CO}_{2}$ retrieval, Atmos. Chem. Phys., 6, 2727-2751, 2006, http://www.atmos-chem-phys.net/6/2727/2006/.

Buchwitz, M., de Beek, R., Burrows, J. P., Bovensmann, H., Warneke, T., Notholt, J., Meirink, J. F., Goede, A. P. H., Bergamaschi, P., Körner, S., Heimann, M., and Schulz, A.: Atmospheric methane and carbon dioxide from SCIAMACHY satellite data: initial comparison with chemistry and transport models, Atmos. Chem. Phys., 5, 941-962, 2005a, http://www.atmos-chem-phys.net/5/941/2005/.

Buchwitz, M., de Beek, R., Noël, S., Burrows, J. P., Bovensmann, H., Bremer, H., Bergamaschi, P., Körner, S., and Heimann, M.: Carbon monoxide, methane and carbon dioxide columns retrieved from SCIAMACHY by WFM-DOAS: year 2003 initial data set, Atmos. Chem. Phys., 5, 3313-3329, 2005b,

http://www.atmos-chem-phys.net/5/3313/2005/.

Buchwitz, M. and Burrows, J. P.: Retrieval of $\mathrm{CH}_{4}, \mathrm{CO}$, and $\mathrm{CO}_{2}$ total column amounts from SCIAMACHY near-infrared nadir spectra: Retrieval algorithm and first results, in: Remote Sensing of Clouds and the Atmosphere VIII, edited by: Schäfer, K. P., Comèron, A., Carleer, M. R., and Picard, R. H. (PDF file available from WFM-DOAS web site http://www.iup.uni-bremen.de/ sciamachy/NIR_NADIR_WFM_DOAS/index.html), Proceedings of SPIE, 5235, 375-388, 2004.

Buchwitz, M., Rozanov, V. V., and Burrows, J. P.: A correlated-k distribution scheme for overlapping gases suitable for retrieval of atmospheric constituents from moderate resolution radiance measurements in the visible/near-infrared spectral region, J. Geophys. Res., 105, 15247-15262, 2000a.

Buchwitz, M., Rozanov, V. V., and Burrows, J. P.: A near-infrared optimized DOAS method for the fast global retrieval of atmospheric $\mathrm{CH}_{4}, \mathrm{CO}, \mathrm{CO}_{2}, \mathrm{H}_{2} \mathrm{O}$, and $\mathrm{N}_{2} \mathrm{O}$ total column amounts from SCIAMACHY Envisat-1 nadir radiances, J. Geophys. Res. 105, 15231-15245, 2000b.

Burrows, J. P., Schneider, W., Geary, J. C., Chance, K. V., Goede, A. P. H., Aarts, H. J. M., de Vries, J., Smorenburg, C., and Visser, H.: Atmospheric remote sensing with SCIAMACHY, Digest of 
Topical Meeting on Optical Remote Sensing of the Atmosphere, Optical Society of America, Washington D.C., 4, 71-74, 1990.

Burrows, J. P. and Chance, K. V. : Scanning imaging absorption spectrometer for atmospheric chartography, Future European and Japanese Remote Sensing Sensors and Programs, edited by: Slater, P. N., Proc. SPIE, 1490, 146-155, 1991.

Burrows, J. P., Hölzle, E., Goede, A. P. H., Visser, H., and Fricke, W.: SCIAMACHY - Scanning Imaging Absorption Spectrometer for Atmospheric Chartography, Acta Astronaut., 35, 7, 445451, 1995.

Crutzen, P. J., Sanhueza, E., and Brenninkmeijer, C. A. M.: Methane production from mixed tropical savanna and forest vegetation in Venezuela, Atmos. Chem. Phys. Discuss., 6, 30933097, 2006,

http://www.atmos-chem-phys-discuss.net/6/3093/2006/.

Dils, B., De Mazière, M., Müller, J. F., Blumenstock, T., Buchwitz, M., de Beek, R., Demoulin, P., Duchatelet, P., Fast, H., Frankenberg, C., Gloudemans, A., Griffith, D., Jones, N., Kerzenmacher, T., Kramer, I., Mahieu, E., Mellqvist, J., Mittermeier, R. L., Notholt, J., Rinsland, C. P., Schrijver, H., Smale, D., Strandberg, A., Straume, A. G., Stremme, W., Strong, K., Sussmann, R., Taylor, J., van den Broek, M., Velazco, V., Wagner, T., Warneke, T., Wiacek, A., and Wood, S.: Comparisons between SCIAMACHY and ground-based FTIR data for total columns of $\mathrm{CO}, \mathrm{CH}_{4}, \mathrm{CO}_{2}$ and $\mathrm{N}_{2} \mathrm{O}$, Atmos. Chem. Phys., 6, 1953-1976, 2006a,

http://www.atmos-chem-phys.net/6/1953/2006/.

Dils, B., De Mazière, M., Blumenstock, T., Hase, F., Kramer, I., Mahieu, E., Demoulin, P., Duchatelet, P., Mellqvist, J., Strandberg, A., Buchwitz, M., Khlystova, I., Schneising, O., Velazco, V., Notholt, J., Sussmann, R., and Stremme, W.: Validation of WFM-DOAS v0.6 $\mathrm{CO}$ and v1.0 $\mathrm{CH}_{4}$ scientific products using European ground-based FTIR measurements, Proceedings of the Third Workshop on the Atmospheric Chemistry Validation of ENVISAT (ACVE-3), 4-7 December 2006, ESA/ESRIN, Frascati, Italy, ESA Publications Division Special Publication SP-642 (on CD; PDF file available from WFMDOAS web site http://www.iup.uni-bremen.de/sciamachy/NIR NADIR_WFM_DOAS/index.html), 2006b.

Dentener, F., Stevenson, D., Cofala, J., Mechler, R., Amann, M., Bergamaschi, P., Raes, F., and Derwent, R.: The impact of air pollutant and methane emission controls on tropospheric ozone and radiative forcing: CTM calculations for the period 19902030, Atmos. Chem. Phys., 5, 1731-1755, 2005,

http://www.atmos-chem-phys.net/5/1731/2005/.

Dueck, T. A., de Visser, R., Poorter, H., Persjin, S., Gorissen, A., de Visser, W., Schapendonk, A., Verhagen, J., Snel, J., Harren, F. J. M., Ngai, A. K. Y., Verstappen, F., Bouwmeester, H., Voesenek, L. A. C. J., and van der Werf, A.: No evidence for substantial aerobic methane emissions by terrestrial plants: ${ }^{13} \mathrm{C}$-labelling approach, New Phytol., 175, 29-35, 2007.

Frankenberg, C., Warneke, T., Butz, A., Aben, I., Hase, F., Spietz, P., and Brown, L. R.: Pressure broadening in the $2 \mathrm{v}_{3}$ band of methane and its implication on atmospheric retrievals, Atmos. Chem. Phys., 8, 5061-5075, 2008a, http://www.atmos-chem-phys.net/8/5061/2008/.

Frankenberg, C., Bergamaschi, P., Butz, A., Houweling, S., Meirink, J. F., Notholt, J., Petersen, A. K., Schrijver, H., Warneke, T., and Aben, I.: Tropical methane emissions: A revised view from SCIAMACHY onboard ENVISAT, Geophys.
Res. Lett., 35, L15811, doi:10.1029/2008GL034300, 2008b.

Frankenberg, C., Meirink, J. F., Bergamaschi, P., Goede, A. P. H., Heimann, M., Körner, S., Platt, U., van Weele, M., and Wagner, T.: Satellite chartography of atmospheric methane from SCIAMACHY onboard ENVISAT: Analysis of the years 2003 and 2004, J. Geophys. Res., 111, D07303, doi:10.1029/2005JD006235, 2006.

Frankenberg, C., Platt, U., and Wagner, T.: Iterative maximum a posteriori (IMAP)-DOAS for retrieval of strongly absorbing trace gases: Model studies for $\mathrm{CH}_{4}$ and $\mathrm{CO}_{2}$ retrieval from near infrared spectra of SCIAMACHY onboard ENVISAT, Atmos. Chem. Phys., 5, 9-22, 2005a,

http://www.atmos-chem-phys.net/5/9/2005/.

Frankenberg, C., Meirink, J. F., van Weele, M., Platt, U., and Wagner, T.: Assessing methane emissions from global spaceborne observations, Science, 308, 1010-1014, 2005b.

Gloudemans, A. M. S., Schrijver, H., Kleipool, Q., van den Broek, M. M. P., Straume, A. G., Lichtenberg, G., van Hees, R. M., Aben, I., and Meirink, J. F.: The impact of SCIAMACHY nearinfrared instrument calibration on $\mathrm{CH}_{4}$ and $\mathrm{CO}$ total columns, Atmos. Chem. Phys., 5, 2369-2383, 2005,

http://www.atmos-chem-phys.net/5/2369/2005/.

Hein, R., Crutzen, P. L., and Heimann, M.: An inverse modeling approach to investigate the global atmospheric methane cycle, Global Biogeochem. Cy., 11, 43-76, 1997.

Herman, J. R., Bhartia, P. K., Torres, O., Hsu, C., Seftor, C., and Celarier, E.: Global distribution of UV absorbing aerosols from Nimbus7/TOMS data, J. Geophys. Res., 102, 16911-16922, 1997.

Houweling, S., Kaminski, T., Dentener, F., Lelieveld, J., and Heimann, M.: Inverse modeling of methane sources and sinks using the adjoint of a global transport model, J. Geophys. Res., 104(D21), 26137-26160, 1999.

Houweling, S., Röckmann, T., Aben, I., Keppler, F., Krol, M., Meirink, J. F., Dlugokencky, E. J., and Frankenberg, C.: Atmospheric constraints on global emissions of methane from plants, Geophys. Res. Lett., 33, L15821, doi:10.1029/2006GL026162, 2006.

IPCC: Houghton, J. T., Ding, Y., Griggs, D. J., Noguer, M., van der Linden, P. J., and Xiaosu, D.: Contribution of working group I to the Third Assessment Report (TAR) of the Intergovernmental Panel on Climate Change (IPCC), Cambridge University Press, Cambridge (UK), New York (USA), 944 pp., 2001.

IPCC: Solomon, S., Qin, D., Manning, M., Chen, Z., Marquis, M., Averyt, K. B., Tignor, M., and Miller, H. L.: Climate change 2007: The physical science basis, Contribution of working group I to the Fourth Assessment Report of the Intergovernmental Panel on Climate Change (IPCC), Cambridge University Press, Cambridge (UK), New York (USA), 996 pp., 2007.

Jenouvrier, A., Daumont, L., Régalia-Jarlot, L., Tyuterev, V. G., Carleer, M., Vandaele, A. C., Mikhailenko, S., and Fally, S.: Fourier transform measurements of water vapor line parameters in the $4200-6600 \mathrm{~cm}^{-1}$ region, J. Quant. Spectrosc. Ra., 105, 326-355, doi:10.1016/j.jqsrt.2006.11.007, 2007.

Keppler, F., Hamilton, J. T. G., McRoberts, W. C., Vigano, I., Braß, M., and Röckmann, T.: Methoxyl groups of plant pectin as a precursor of atmospheric methane: evidence from deuterium labelling studies, New Phytol., 178, 808-814, doi:10.1111/j.14698137.2008.02411.x, 2008. 
Keppler, F., Hamilton, J. T. G., Braß, M., and Röckmann, T.: Methane emissions from terrestrial plants under aerobic conditions, Nature, 439, 187-191, 2006.

Kleipool, Q. L., Jongma, R. T., Gloudemans, A. M. S., Schrijver, H., Lichtenberg, G. F., van Hees, R. M., Maurellis, A. N., and Hoogeveen, R. W. M.: In-flight proton-induced radiation damage to SCIAMACHY's extended-wavelength InGaAs near-infrared detectors, Infrared Phys. Techn., 50, 30-37, 2007.

Krol, M., Houweling, S., Bregman, B., van den Broek, M., Segers, A., van Velthoven, P., Peters, W., Dentener, F., and Bergamaschi, P.: The two-way nested global chemistry-transport zoom model TM5: algorithm and applications, Atmos. Chem. Phys., 5, 417432, 2005, http://www.atmos-chem-phys.net/5/417/2005/.

Lelieveld, J.: A nasty surprise in the greenhouse, Nature, 443, 405406, 2006.

Meirink, J. F., Bergamaschi, P., and Krol, M. C.: Four-dimensional variational data assimilation for inverse modelling of atmospheric methane emissions: method and comparison with synthesis inversion, Atmos. Chem. Phys., 8, 6341-6353, 2008a, http://www.atmos-chem-phys.net/8/6341/2008/.

Meirink, J. F., Bergamaschi, P., and Frankenberg, C., et al.: Four-dimensional variational data assimilation for inverse modeling of atmospheric methane emissions: Analysis of SCIAMACHY observations, J. Geophys. Res., 113, D17301, doi:10.1029/2007JD009740, 2008b.

Meirink, J. F., Eskes, H. J., and Goede, A. P. H.: Sensitivity analysis of methane emissions derived from SCIAMACHY observations through inverse modelling, Atmos. Chem. Phys., 6, 1275-1292, 2006, http://www.atmos-chem-phys.net/6/1275/2006/.

Mikaloff Fletcher, S. E., Tans, P. P., Bruhwiler, L. M., Miller, J. B., and Heimann, M.: $\mathrm{CH}_{4}$ sources estimated from atmospheric observations of $\mathrm{CH}_{4}$ and its ${ }^{13} \mathrm{C} /{ }^{12} \mathrm{C}$ isotopic ratios: 1 . Inverse modeling of source processes, Global Biogeochem. $\mathrm{Cy}$., 18, GB4004, doi:10.1029/2004GB002223, 2004a.

Mikaloff Fletcher, S. E., Tans, P. P., Bruhwiler, L. M., Miller, J. B., and Heimann, $\mathrm{M}$.: $\mathrm{CH}_{4}$ sources estimated from atmospheric observations of $\mathrm{CH}_{4}$ and its ${ }^{13} \mathrm{C} /{ }^{12} \mathrm{C}$ isotopic ratios: 2. Inverse modeling of $\mathrm{CH}_{4}$ fluxes from geographical regions, Global Biogeochem. Cy., 18, GB4005, doi:10.1029/2004GB002224, 2004b.

Miller, J. B., Gatti, L. V., d'Amelio, M. T. S., Crotwell, A. M., Dlugokencky, E. J., Bakwin, P., Artaxo, P., and Tans, P. P.: Airborne measurements indicate large methane emissions from the eastern Amazon basin, Geophys. Res. Lett., 34, L10809, doi:10.1029/2006GL029213, 2007.
Noël, S., Buchwitz, M., and Burrows, J. P.: First retrieval of global water vapour column amounts from SCIAMACHY measurements, Atmos. Chem. Phys., 4, 111-125, 2004, http://www.atmos-chem-phys.net/4/111/2004/.

Peters, W., Jacobson, A. R., Sweeney, C., Andrews, A. E., Conway, T. J., Masarie, K., Miller, J. B., Bruhwiler, L. M. P., Pétron, G., Hirsch, A. I., Worthy, D. E. J., van der Werf, G. R., Randerson, J. T., Wennberg, P. O., Krol, M. C., and Tans, P. P.: An atmospheric perspective on North American carbon dioxide exchange: CarbonTracker, Proceedings of the National Academy of Sciences (PNAS) of the United States of America, 27 November 2007, 104, 48, 18925-18930, 2007.

Press, W., Teukolsky, S., Vetterling, W., and Flannery, B.: Numerical Recipes in Fortran, Cambridge University Press, London, 963 pp., 1992.

Rigby, M., Prinn, R. G., Fraser, P. J., Simmonds, P. G., Langenfels, R. L., Huang, J., Cunnold, D. M., Steele, L. P., Krummel, P. B., Weiss, R. F., O’Doherty, S., Salameh, P. K., Wang, H. J., Harth, C. M., Mühle, J., and Porter, L. W.: Renewed growth of atmospheric methane, Geophys. Res. Lett., 35, L22805, doi:10.1029/2008GL036037, 2008.

Rothman, L. S., Barbe, A., Benner, D. C., Brown, L. R., CamyPeyret, C., Carleer, M. R., Chance, K., Clerbaux, C., Dana, V., Devi, V. M., Fayt, A., Flaud, J. M., Gamache, R. R., Goldman, A., Jacquemart, D., Jucks, K. W., Lafferty, W. J., Mandin, J. Y., Massie, S. T., Nemtchinov, V., Newnham, D. A., Perrin, A., Rinsland, C. P., Schroeder, J., Smith, K. M., Smith, M. A. H., Tang, K., Toth, R. A., Vander Auwera, J., Varanasi, P., and Yoshino, K.: The HITRAN molecular spectroscopic database: edition of 2000 including updates through 2001, J. Quant. Spectrosc. Ra., 82, 5-44, 2003.

Rothman, L. S., Jacquemart, D., and Barbe, A., et al.: The HITRAN 2004 molecular spectroscopic database, J. Quant. Spectrosc. Ra., 96, 139-204, 2005.

Schneising, O., Buchwitz, M., Burrows, J. P., Bovensmann, H., Reuter, M., Notholt, J., Macatangay, R., and Warneke, T.: Three years of greenhouse gas column-averaged dry air mole fractions retrieved from satellite - Part 1: Carbon dioxide, Atmos. Chem. Phys., 8, 3827-3853, 2008a, http://www.atmos-chem-phys.net/8/3827/2008/.

Schneising, O., Buchwitz, M., Burrows, J. P., Bovensmann, H., Bergamaschi, P., and Peters, W.: Three years of greenhouse gas column-averaged dry air mole fractions retrieved from satellite Part 2: Methane, Atmos. Chem. Phys. Discuss., 8, 8273-8326, 2008b, http://www.atmos-chem-phys-discuss.net/8/8273/2008/. 